Research Article

\title{
The Impact of Government Subsidies on Private R\&D Investment in Different Markets
}

\author{
Jinglve Wang $(\mathbb{D})$ and Guohua Zhou $(\mathbb{D}$ \\ School of Economics and Management, Southwest Jiaotong University, SWJTU, Chengdu, China \\ Correspondence should be addressed to Guohua Zhou; ghzhou@126.com
}

Received 8 March 2020; Revised 19 May 2020; Accepted 29 May 2020; Published 4 July 2020

Academic Editor: Anna M. Gil-Lafuente

Copyright (c) 2020 Jinglve Wang and Guohua Zhou. This is an open access article distributed under the Creative Commons Attribution License, which permits unrestricted use, distribution, and reproduction in any medium, provided the original work is properly cited.

\begin{abstract}
In contrast to the econometric models that have been commonly used throughout a large portion of the literature, we develop six game-theoretic models to analyze governmental subsidy strategies in different market environments and to investigate the question of whether government subsidies crowd in or crowd out private investment in R\&D activities. Based on realistic situations, we classify governmental subsidy strategies into three types, namely, no subsidy provided, subsidies provided based on the price of the end products, and subsidies provided based on the cost of R\&D. In addition, according to whether competition exists in the market, we classify markets into monopoly markets and duopoly markets. Our research shows (a) that the relationship between government subsidies and private R\&D investment is deeply impacted by the form of the subsidies used; (b) that the characteristic value of the $\mathrm{R} \& \mathrm{D}$ project and the competitive environment of the market are the two key factors that should be considered when governments decide which form of subsidy to employ; and (c) the optimal amount for each type of subsidy.
\end{abstract}

\section{Introduction}

According to the neoclassical theory, the "public good" characteristic of R\&D activities makes private R\&D expenditure systematically lower than the socially optimal level [1]. As a result, government subsidies play a central role in virtually all developed or developing countries. For example, to incentivize more companies to engage in the development of 5G technology, the Sichuan province promises that the local government will subsidize $20 \%$ of the costs that innovators incur [2]. Each firm that engages in R\&D in Erdos, a city in northwest China, will obtain capital support equal to $5 \%$ of its R\&D cost [3]. From 2000 to 2015, the United States Federal Government granted subsidies to corporations of at least 68 billion dollars by way of grants, tax credits, etc., and 582 large companies received $67 \%$ of the total amount [4]. In fact, many governments throughout the world use R\&D subsidies to stimulate private R\&D investment. Figure 1, which contains data from SRIT DRCNET (http://www. drcnet.com.cn), shows the proportions of government (GO) and enterprise (CO.) investment in the R\&D expenditure of enterprises in some countries. It can be seen from this figure that, regardless of the level of development in a country, the governments in these countries subsidize enterprise innovation activities. However, there does not seem to be an obvious pattern between the proportion of government investment and the proportion of corporate investment. Taking Mexico as an example, the proportion of government investment in corporate R\&D expenditures increased year by year from 2011 to 2015, but the proportion of corporate investment did not show the same trend.

The past two decades have witnessed an ongoing debate about the effectiveness of government subsidies [5]. However, there has been no consensus. Some scholars point out that government subsidies have a 'crowding-in effect' on the R\&D investment of private enterprises. The reason why private enterprises have little enthusiasm for and underinvest in R\&D is because of the low payoff and high cost of R\&D. Government subsidies-whether they are increasing the profitability of the end product or decreasing the cost of $\mathrm{R} \& \mathrm{D}$ activities - can help to mitigate the cost of private $\mathrm{R} \& \mathrm{D}$ and spur private companies to invest in R\&D. Other scholars 


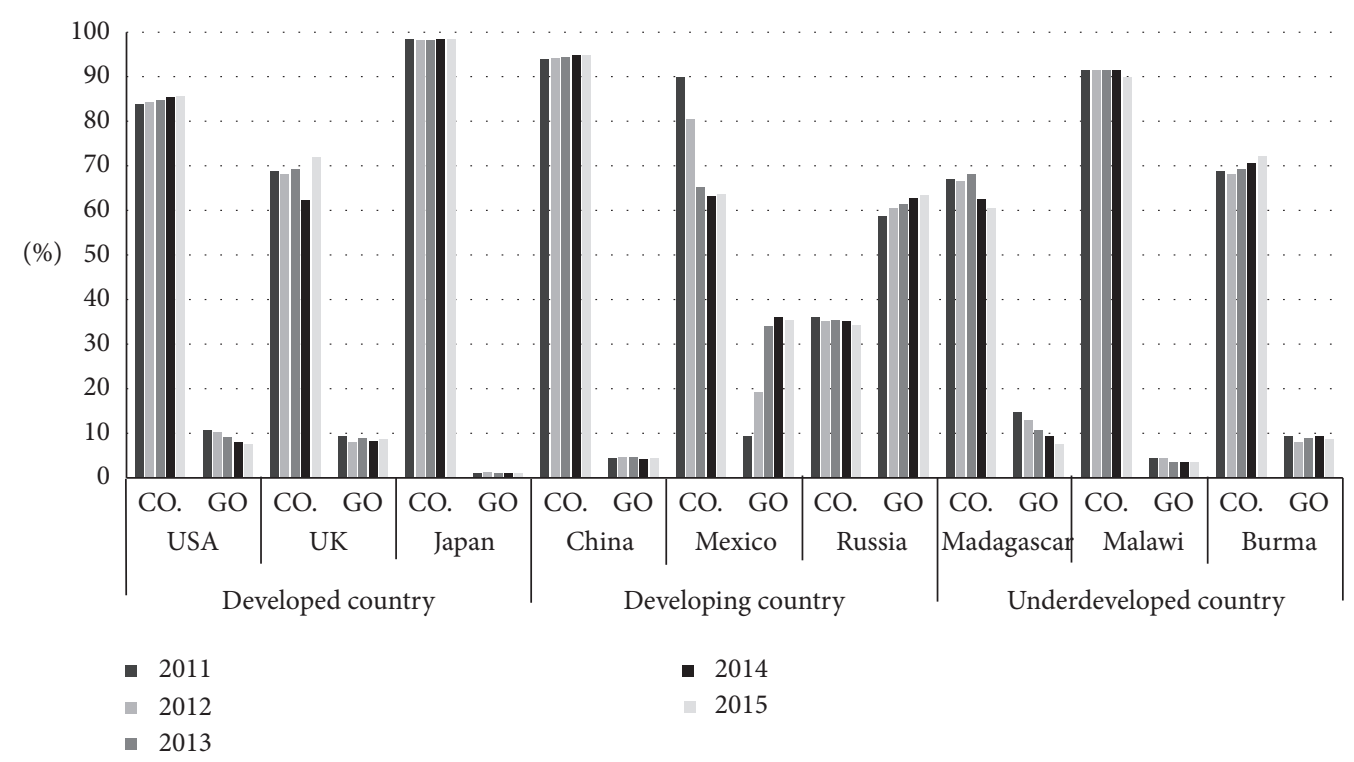

FIGURE 1: Proportions of government and enterprise investment in the R\&D expenditures of companies.

hold the view that government subsidies will crowd out private companies' investment in R\&D. They argue that subsidized companies will replace their R\&D spending with government subsidies, which means that the total investment in R\&D does not increase.

The mixed findings of prior studies drive us to determine a new way of explaining the relationship between government subsidies and private R\&D investment. To achieve this goal, we abandon the econometric models that have been commonly used in much of the literature and instead use game theory to analyze the micro decision-making process used for R\&D financing. There are two main reasons for this change. First, a sequence of decisions made by governments and firms each contributes to the impact of government subsidies on private R\&D investment. Therefore, if we want to determine the influence mechanism between government subsidies and private $\mathrm{R} \& \mathrm{D}$, the best way to make this determination is to analyze the decision-making process involving subsidies and the governments' and firms' optimal decisions. For governments, the first decision is whether to subsidize private R\&D. If governments decide to subsidize private $R \& D$, the next decision to be made is which type of subsidy should be adopted. After that, governments should also decide which subsidy rate is optimal for the specific situation. Following these governmental decisions, private firms that are engaged in $R \& D$ will set the optimal target level of technology development for their company and the best price for the new technology produced. Manufacturers who buy the new technology and apply it to their product should also set the optimal price of their end products. In this paper, we provide systematic explanations about the impact of government subsidies on private R\&D investment by analyzing the decision process of governments and private firms.

Furthermore, both governments and firms aim to maximize their interests in the decision-making process [6]. Although the sequence of decision-making steps and the results of the decisions may be different, the purposes of governments and firms never change. Governments offer R\&D subsidies to maximize social welfare [7], while firms aim to maximize their expected profit [8]. Once we grasp the purposes of governments and firms, we can analyze and anticipate their decision results and then determine the impact of government subsidies on private R\&D investment.

In this paper, three factors impacting the decisionmaking process of governments and firms are examined. First, the type of government subsidy is studied. It is well known that there are many subsidy types for governments to choose from. For example, to simulate technology development in the field of green energy, the Chinese government provided a subsidy to consumers who bought a new energy automobile in 2018. The government also provides lowinterest loans to innovative companies in other fields to encourage their R\&D investment. In this paper, the various kinds of subsidies are classified into two types-subsidies that are provided based on the price of the end products produced and subsidies that are provided based on the cost of the $R \& D$ required [9]. Additionally, we design three government subsidy strategies, namely, (a) no subsidy of R\&D activities (strategy N), (b) subsidies of R\&D activities based on the price of the manufacturer's products (strategy $\mathrm{P}$ ), and (c) subsidies of R\&D activities based on the cost of the $\mathrm{R} \& \mathrm{D}$ required (strategy $\mathrm{C}$ ).

In addition, the market environment also influences the decision-making process of subsidies and subsequently influences the impact of government subsidies on private $R \& D$ investment. We divide market environments into two types-monopoly markets and duopoly markets. In a monopoly market, an innovator sells her new technology to only one manufacturer, and that manufacturer then applies the new technology to his products and sells the products to consumers. This is the case in China's bullet train market, where the technology developed by the China Academy of Railway Sciences is sold only to the CRRC Corporation 
Limited, which is the sole manufacturer of bullet trains. In a duopoly market, an innovator sells her new technology to two manufacturers who sell similar products in the same market. For example, the PC market consists of Intel and other computer manufacturers. In this paper, we compare the impact of government subsidies on private $R \& D$ investment in these two kinds of markets.

Finally, uncertainty influences the subsidy decision-making process. There are different kinds of uncertainty involved in the process of R\&D. Technological development may be a success or a failure. Even if firms make a successful breakthrough in technological development, the new technology may not be successful in increasing product sales. Because of these factors, we model the uncertainty of the R\&D process from the perspective of quality improvement efficacy and the R\&D cycle.

The first important message of our paper is that the relationship between government subsidies and private $\mathrm{R} \& \mathrm{D}$ investment is deeply impacted by the form of the subsidy used. When governments subsidize private $R \& D$ based on the price of the end products, the government subsidy will have a crowding-in effect on private R\&D investment, and this effect will increase with the amount of subsidy. When governments subsidize private R\&D activities based on the cost of the R\&D involved, the subsidy will have a crowding-in effect on private $\mathrm{R} \& \mathrm{D}$ investment at first, but with an increase in the amount of the subsidy, the crowding-in effect will gradually transform to a crowdingout effect. In addition, this paper notes the factors that should be considered when governments decide which subsidy forms to use. By contrasting the three subsidy strategies, we find that the technology transfer rate, the R\&D cycle, and the competitive environment of the market should be considered seriously when governments choose which form of subsidy to use. Third, we determine the optimal amount of government subsidies and the best decisions that private firms can make in a balanced situation.

To summarize, our research contributes to the literature by analyzing the optimal decisions for governments and private firms regarding the incentive process of $\mathrm{R} \& \mathrm{D}$, which benefits not only supply chain parties and consumers but also policymakers. To the best of our knowledge, this is the first model that jointly considers different subsidy strategies and different markets.

We organize the remainder of this paper as follows. The literature is reviewed in Section 2. Section 3 presents the model settings. Sections 4 and 5 analyze the optimal decisions of private firms and governments in both a monopoly market and a duopoly market. We also conduct a contrastive analysis of governments' subsidizing strategies and the impact of government subsidies on private R\&D investment in different markets in Sections 4 and 5. In Section 6, we conduct an empirical analysis of the impact of the subsidy strategy $C$ on the private $R \& D$ investment use panel data from China's A-share market. Finally, Section 7 provides concluding remarks and suggestions for future research.

\section{Literature Review}

This paper is closely related to two streams of the literature, namely, the industrial economics and operations management literature, as it concerns the impact of government subsidies on private R\&D investment and the micro decision-making process.

The impacts of government subsidies on private R\&D investment have been examined empirically and theoretically in the literature. However, there is neither theoretical nor empirical definitive guidance on the effectiveness of government subsidies in stimulating private R\&D [10]. For example, using data from the Korean pharmaceutical industry, Choi et al. find that government subsidies stimulate rather than crowd out private $R \& D$ activities of small biotechnology venture firms [11]. Chen and Gupta find that an increase in the credit rate has a positive effect on the R\&D spending of high-tech firms with a taxable status but does not have the same positive effect on firms that are not high tech [12]. Similarly, Colombo and Croce's work finds that the investments of small new technology-based firms are sensitive to internal cash flow and that the receipt of public subsidies results in an increased investment rate for these firms as well as reduced investment-cash flow sensitivity [13]. Czarnitzki and Toole find that product market uncertainty reduces $\mathrm{R} \& \mathrm{D}$ investment and that government R\&D subsidies increase $R \& D$ investment by analyzing a sample of German manufacturing firms [14]. Czarnitzki and Toole also note that when receiving subsidies, Finnish companies showed R\&D and patenting activity, while the firms not receiving subsidies would have performed significantly better if they had been publicly funded [15].

Although these findings provide empirical evidence that government subsidies can successfully address market failure in private $R \& D$ investment and can stimulate private R\&D activities [12, 16, 17], a large number of studies show that $\mathrm{R} \& \mathrm{D}$ subsidies displace or take the place of private $\mathrm{R} \& \mathrm{D}$ efforts rather than stimulating them [18-21]. For instance, Marino et al. analyze the effect of public R\&D subsidies on private $R \& D$ expenditures in a sample of French firms during the period 1993-2009, and their study finds that these crowding-out effects appear to be more pronounced in companies receiving medium-high levels of public subsidies and, generally, in companies under the R\&D tax credit system [18]. Yu et al. find that government subsidies have a significant crowding-out influence on enterprises' $R \& D$ investment behavior and that this influence is further moderated by the attributes of enterprise ownership [22].

Furthermore, some studies suggest mixed results. To illustrate, by analyzing data from 269 information technology entrepreneurial firms in China, Chen et al. find that R\&D subsidies have an inverted U-shaped effect on IPO performance [5]. Dai and Cheng point out that public subsidies follow an S-shaped relationship and inverted-U correlation with the firm's total $R \& D$ and private $R \& D$ investment, respectively. Boeing investigates the allocation of China's R\&D subsidies and their effectiveness in stimulating business $R \& D$ investments for a sample of Chinese listed firms between 2001 and 2006; he finds that R\&D subsidies crowd out business R\&D investment in the immediate term but are neutral in later periods [23]. The empirical literature is generally not based on theoretical models that capture the strategic decisions made by the firms 
and government agencies that constitute an essential part of an innovation policy environment [24]. Thus, this paper attempts to explain the impact of government subsidies on private $\mathrm{R} \& \mathrm{D}$ from the perspective of the micro decisionmaking process.

There is a stream of literature that addresses incentive mechanisms and price decision-making for R\&D in supply chains. In the supply chains, each member attempts to maximize its profit, and these attempts may not coincide with the optimal decisions for the entire system [25]. Therefore, the main purpose of the decision research regarding this topic is to determine a balanced solution for each member.

In reviewing the micro decision-making process literature, we see extensive literature focusing on the optimal R\&D effort decision and the optimal price decision. For example, Xiao and $\mathrm{Xu}$ investigate the impact of royalty revision on incentives and profits in a two-stage alliance with a marketer and an innovator. They find that the potential for royalty revision leads to more severe distortions in the optimal initial royalty contracts offered by the marketer [26]. Using an infinite-horizon two-player differential game, Breton et al. derive and compare Bertrand and Cournot equilibria for a differentiated duopoly engaging in $R \& D$ competition [27].

For the examination of the impact of government subsidies on private $\mathrm{R} \& \mathrm{D}$, game theory and other theorybased models are used less often, but some studies do exist (e.g., $[9,28,29])$. The closest studies to the research of our paper are $[24,30]$. Chen et al. endogenize government subsidies in a research joint venture and analyze a threeplayer game. They draw our attention to different types of supply chain structures and subsidies [30]. However, their research does not consider the impact of product competition on players' decisions. Takalo et al. extend the theoretical basis of the empirical literature on the effects of $\mathrm{R} \& \mathrm{D}$ subsidies by providing an estimable model of strategic interaction among subsidy applicants and public and private sector R\&D financiers [24]. The main weakness of their study is that they overlook the competitive and uncertain environment inherent to the process of $\mathrm{R} \& \mathrm{D}$.

Our paper differs from the abovementioned studies in three ways: (1) it utilizes a competitive market environment considering the competitive relationship between manufacturers; (2) it employs a contrastive analysis of the different types of subsidies; and (3) it provides a systematic interpretation of the impact of government subsidies on private $\mathrm{R} \& \mathrm{D}$ investment.

\section{Model Setting}

The supply chain for our model consists of an innovator (company $F$, she) and a manufacturer (company $P$, he). The innovator implements technological innovation and sells new technology to the manufacturer. The manufacturer uses these new techniques to improve the quality of his product. As a result, the sales of the manufacturer's product will increase.
3.1. Model of Innovation. The innovator sets the level of innovation $\theta$ that she wants to achieve. As $\theta$ increases, the innovator will make greater technological progress, and the manufacturer's product quality will improve and thus become more profitable. We assume that there is a one-to-one correspondence between the level of innovation and the additional demand for products. In particular, we model that an innovation level $\theta$ generates an incremental demand of $r \theta$, and the original demand of the product before the innovation is set at 1 . Then, the total demand after the innovation is successful can be represented as

$$
d=1+r \theta-p
$$

where $p>0$ is the retail price of the manufacturer's product.

The innovation in our model does not increase the firm's marginal costs; however, it incurs a variable time-dependent cost of resource deployment to complete the innovation [31]. To account for the fact that a higher level of innovation requires more resources, we assume that these costs are proportional to $\theta$. Additionally, because the salary of personnel, the depreciation of research equipment, and the rental cost of office space all increase during the R\&D cycle, we assume that these costs are proportional to the development time. Specifically, we model these $\operatorname{costs}$ as $\operatorname{ct} \theta$, where $c$ is a constant and $t$ is the total time taken for technological innovation. Thus, the cost function of innovation would be

$$
C=c t \theta \text {. }
$$

Note that we assume that the application cost of the new technology to the manufacturer's products is zero. We make this assumption based on three factors. First, compared with the cost of technology development, the cost of applying new technology to existing products is relatively low. For instance, when the cellphone manufacturer Huawei applies facial recognition technology to his cellphones, he simply must update these cellphones' operation systems through the Internet, which means that the application cost is close to zero. Second, from the perspective of model analysis, the main purpose of this paper is to analyze the optimal decisions of innovators, manufacturers, and governments regarding the process of technology development. Not only is it illogical to consider the application cost but it also complicates the model. Third, the consideration of the application cost does not make a substantial difference in the conclusions. In fact, a stream of literature assumes that the application cost is zero such as [31-33].

3.2. Model of Uncertainty. An increasing number of studies have shown that uncertainty has played a critical role in the process of innovation $[34,35]$. Due to the uncertainty of the external environment and technology itself, it is impossible to predict the outcome of R\&D activities precisely. Before the completion of $R \& D$ activities, whether innovation can effectively improve the quality of a product is unknown, as is the R\&D cycle itself.

First, we model the uncertainty of quality improvement efficacy. We assume that at the beginning of technology development, the innovator only has an estimate of the 
efficacy of the new technology, which represents the desired outcome of the technology development. The efficacy shows the extent to which an innovator can exploit the new technology to improve the quality of the manufacturer's products. We refer to this efficacy as quality improvement efficacy and use $\widetilde{v}$ to represent it. Therefore, the resulting level of quality improvement after the completion of technology development would be $\widetilde{v} \theta$, where $\widetilde{v}$ is uniformly distributed between $\underline{v}$ and 1 . As $\underline{v}$ approaches 1 , product quality increases. This increase characterizes the efficacy of the uncertainty in the development process. Combining the above information with the assumption in 3.1, we can rewrite the total demand function after innovation as

$$
d=1+r \tilde{v} \theta-p
$$

In addition, the R\&D cycle of technology development is also uncertain and depends on the innovator's capability and the level of innovation that the innovator wants to achieve. Following prior research, we assume that the $R \& D$ cycle $t$ is exponentially distributed and has a probability density function $f(t)=g(\lambda, \theta) e^{-g(\lambda, \theta) t}$. The $g(\lambda, \theta)$ is the development rate, which represents the time taken for technology development, and is assumed to be a function of the innovator's capability $\lambda$-thus directly impacting the speed of the development-and the level of quality of the improvement $\theta$ undertaken by the innovator. Because more time would be required for developing a higher quality product, we assume that $g(\lambda, \theta)$ is decreasing in $\theta$. In particular, we use the functional form $g(\lambda, \theta)=\lambda \theta^{-1}$ [31].

For brevity, we assume that the price elasticity of the manufacturer's products is 1 . This assumption is common in supply chain research. Raz, Chen, and Özdemir make the same assumption in their studies [9, 30, 36]. Moreover, through trial calculation, we find that although the optimal subsidy amount of the government will change slightly under different price elasticities, there are no substantial differences between different price elasticities.

In addition, in this paper, we choose a monopoly and a duopoly market to analyze the impact of government subsidies on private $\mathrm{R} \& \mathrm{D}$ investment. There are three considerations underlying this choice. First, in the field of technological innovation, due to technical barriers, duopoly markets are common. For instance, although there are many other third-party payment companies in China, Alibaba and Tencent account for $93.11 \%$ of the market share during the third quarter of 2019, according to an analysis report. Similar situations have also occurred involving Gree and Midea in the air-conditioning market and Boeing and Airbus in aviation. Second, differentiating between these two kinds of markets can make the analysis process clear and easy. The influences of the features of innovation can be explored deeply in a monopoly market without the interference of other factors. Based on the conclusions reached under a monopoly market, the influence of competitive intensifiers on equilibrium can be analyzed clearly in a duopoly market. Third, there are many mature theories in the research on monopoly and duopoly markets, which not only help us to establish and analyze the game model but also help to extend these research conclusions to other market types.

\section{Monopoly Market}

In a monopoly market, there is only one innovator and one manufacturer in the supply chain. The innovator engages in R\&D and sells the resulting new technology to the manufacturer. Then, the manufacturer applies the new technology to his products and sells his products to consumers. The government has three strategies to incentivize private $R \& D$ : (a) no subsidization of R\&D activities (strategy MN), (b) subsidization of R\&D based on the price of the manufacturer's products (strategy MP), and (c) subsidization of R\&D based on the cost of the R\&D (strategy MC), as depicted in Figure 2. The letter $T$ stands for the new technology, the letter $R$ stands for revenues, and the letter $S$ stands for government subsidies.

4.1. Strategy MN. When the government does not subsidize private $\mathrm{R} \& \mathrm{D}$, the game sequence can be stated as follows:

Step 1: the innovator sets the level of the innovation $\theta$ and the price of the new technology $w$

Step 2: the manufacturer sets the price of the end products $p$

Step 3: consumers buy the end products; the innovator, the manufacturer, and the government gain revenues

The expected revenues are denoted as $\prod_{F}^{M N}, \prod_{P}^{M N}$, and $\prod_{G}^{M N}$ for the innovator, the manufacturer, and the government when the government does not subsidize R\&D, respectively. The $M$ superscript indicates the monopoly market. The $N$ superscript indicates no subsidy. The profit functions can be written as follows:

$$
\begin{gathered}
\prod_{F}^{M N}=w(1+v r \theta-p)-\frac{c \theta^{2}}{\lambda}, \\
\prod_{P}^{M N}=(p-w)(1+v r \theta-p), \\
\prod_{G}^{M N}=\prod_{F}^{M N}+\prod_{P}^{M N}+\frac{1}{2}(1+v r \theta-p)^{2},
\end{gathered}
$$

where $v=E(\widetilde{v})=(1+\underline{v}) / 2$, similarly hereafter. Following prior studies, we assume that the government's revenue consists of the innovator's and the manufacturer's profits $\prod_{F}^{M N}+\prod_{P}^{M N}$ and the consumer surplus $(1 / 2)(1+v r \theta-p)^{2}$ [37-39].

The game outcomes are provided in Proposition 1. To ensure the coexistence of the innovator and the manufacturer in the market, $(c / \lambda)>(1 / 8) r^{2} v^{2}$ is required. Thus, in the following analysis, we assume $K=\left(\Delta^{2} / \eta\right)<8$, where $\Delta=$ $r v$ and $\eta=c / \lambda$. According to the model setting, the parameter $K$ represents the ratio of the economic conversion rate of technology development to the R\&D cycle cost of technology development. $K$ represents the characteristic 


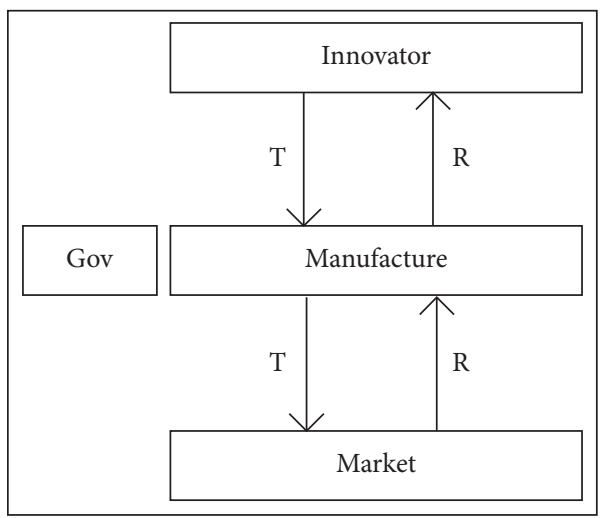

(a)

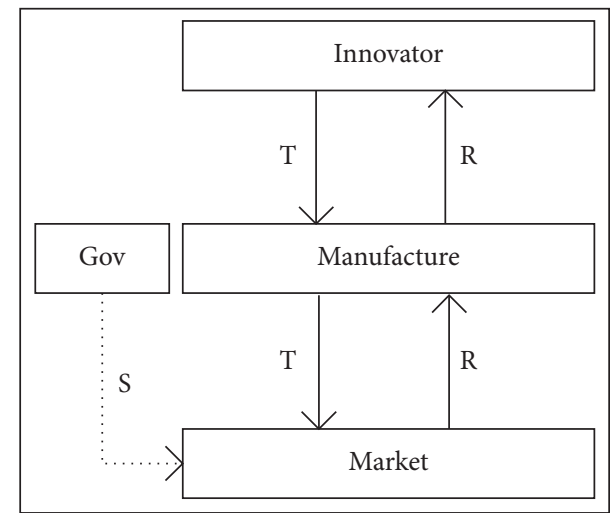

(b)

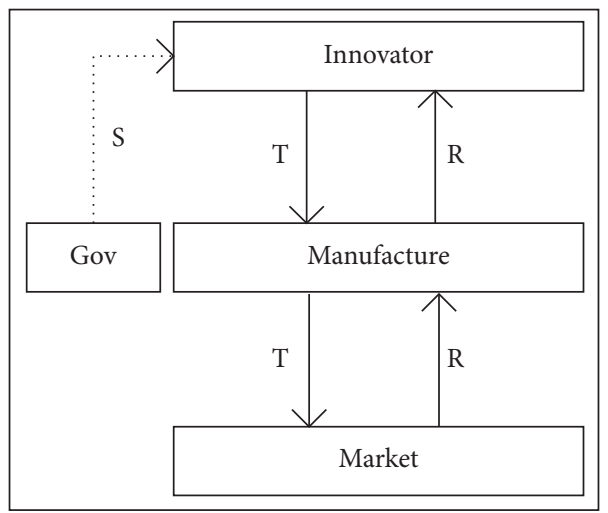

(c)

Figure 2: The government's three subsidy strategies in a monopoly market. (a) Strategy MN. (b) Strategy MP. (c) Strategy MC.

value of the innovation project. In the interest of saving space, we include some of the detailed proofs in the Appendix. Let superscript $*$ denote the optimal solutions.

Proposition 1. The outcomes of the game assuming a monopoly market and that the government does not subsidize private R\&D are shown in Table 1.

4.2. Strategy MP. When the government chooses to subsidize R\&D based on the price of the end products, the game sequence can be stated as follows:

Step 1: by referring to the price of the old version of the end products and estimating the social benefits of the additional $\mathrm{R} \& \mathrm{D}$, the government determines the subsidy $\mu$, where $\mu \in(0, p)$. Because of this subsidy, consumers buy the new version of products at the price of $p-\mu$, and then the market demand is $d=1+\tilde{v} r \theta-(p-\mu)$. The government's total subsidy is $\mu d$.

Step 2: the innovator sets the target level of innovation $\theta$ and the price of the new technology $w$.

Step 3: the manufacturer sets the price of the end product $p$.

Step 4: consumers buy the product; the innovator, the manufacturer, and the government gain revenue.

The expected profits are denoted as $\prod_{F}^{M P}, \prod_{P}^{M P}$, and $\prod_{G}^{M P}$ for the innovator, the manufacturer, and the government when the government subsidizes R\&D based on the price of the end products, respectively. The $M$ superscript indicates the monopoly market. The $P$ superscript indicates the subsidy based on the price of the manufacturer's end product. The profit functions can be written as follows:

$$
\prod_{F}^{M P}=w(1+v r \theta+\mu-p)-\frac{c \theta^{2}}{\lambda}, \prod_{P}^{M P}=(p-w)(1+v r \theta+\mu-p), \prod_{G}^{M P}=\prod_{F}^{M P}+\prod_{P}^{M P}+\frac{1}{2}(1+v r \theta+\mu-p)^{2}-\mu(1+v r \theta+\mu-p) .
$$


TABLE 1: Outcomes of the game under strategy $\mathrm{MN}$ in a monopoly market.

\begin{tabular}{lccccc}
\hline$\theta^{M N^{*}}$ & $w^{M N^{*}}$ & $p^{M N^{*}}$ & $\prod_{F}^{M N *}$ & $\prod_{P}^{M N^{*}}$ & $\prod_{G}^{M N^{*}}$ \\
\hline$\Delta / 8 \eta-\Delta^{2}$ & $4 \eta / 8 \eta-\Delta^{2}$ & $6 \eta / 8 \eta-\Delta^{2}$ & $\eta / 8 \eta-\Delta^{2}$ & $4 \eta^{2} /\left(8 \eta-\Delta^{2}\right)^{2}$ & $\eta\left(14 \eta-\Delta^{2}\right) /\left(8 \eta-\Delta^{2}\right)^{2}$ \\
\hline
\end{tabular}

Proposition 2. The outcomes of the game assuming a monopoly market and that the government subsidizes private $R \ll D$ based on the price of products are shown in Table 2.

Based on the abovementioned outcomes, we can offer the following propositions.

Proposition 3. In a monopoly market, if the government subsidizes private R\&D based on the price of the end products, both the innovator's optimal target level of innovation and the optimal price of new technology are positively correlated with the government subsidy.

Proposition 3 provides the following insight. A subsidy based on the price of the end products can effectively encourage the innovator to set a higher $\mathrm{R} \& \mathrm{D}$ goal. In other words, it is possible to stimulate R\&D by subsidizing based on the price of the end products. Proposition 3 is consistent with prior studies, such as $[40,41]$.

Proposition 4. In a monopoly market, if the government subsidizes private R\&D based on the price of the end products, the subsidy has a crowding-in effect on private ReD investment.

The private investment in R\&D is denoted as $Y C^{M N}$ and $Y C^{M P}$ under strategy $\mathrm{MN}$ and strategy MP in a monopoly market, respectively. According to Propositions 1 and 2, $Y C^{M N}=c \theta^{2} / \lambda=K /(8-K)^{2}$ and $Y C^{M P}=c \theta^{2} / \lambda=K(1+$ $\mu)^{2} /(8-K)^{2}$. Because $0<\mu<p, \quad Y C^{M P}-Y C^{M N}=\mu(\mu+$ 2) $K /(8-K)^{2}>0$.

Proposition 4 demonstrates that when the government subsidizes private $\mathrm{R} \& \mathrm{D}$ based on the price of the end products, the innovator will increase her investment in R\&D. Furthermore, note that $\partial\left(Y C^{M P}-Y C^{M N}\right) / \partial \mu>0$ indicates that the crowding-in effect becomes stronger with an increase in government subsidies. Figure 3 depicts the crowding-in effect of government subsidies.

Proposition 4 shows that subsidies based on the price of the end products always stimulate private $\mathrm{R} \& \mathrm{D}$ investment. Many prior empirical research results support Proposition 4. Chen et al. point out that government subsidies have a positive effect on high-tech companies' R\&D activities [12]. Aerts et al. also point out that companies that are subsidized by the government are more willing to carry out R\&D activities [42]. One of the reasons that subsidies which are based on the price of the end products always crowd in private $R \& D$ investment is that, in this situation, the subsidy works through the market, as is shown in Figure 4. For the innovator, there is no other way to gain the subsidy but to participate in the supply chain through implementing R\&D activities.
However, there is a drawback to this type of subsidy. By comparing the prices of products before and after subsidies are implemented, we find that the manufacturer charges a higher retail price $\left(p^{M N^{*}}=6 \eta / 8 \eta-\Delta^{2}\right.$ and $p^{M P^{*}}=6 \eta(\mu+$ $1) / 8 \eta-\Delta^{2}$ ), which means that a large part of the subsidy remains with the manufacturer.

Proposition 5. In a monopoly market, there is a threshold $K^{M P}=2$ such that the government will subsidize private R\&D through a subsidy based on the price of the end products if and only if (iff) $0<K<K^{M P}$.

The added value of the government's revenue is denoted as $M_{G}^{M P}$ under the strategy of MP in a monopoly market, $M_{G}^{M P}=\prod_{G}^{M P^{*}}-\prod_{G}^{M N^{*}}=36 /(2-K)(8-K)^{2}$. It follows that $M_{G}^{M P}>0$ if $0<K<2$ and $M_{G}^{M P}<0$ if $2<K<8$.

Proposition 5 shows an interval of $K$ in which the government will subsidize private R\&D activities. Figure 5 depicts the interval. The dash-dot line represents the government's revenue after subsidizing private $\mathrm{R} \& \mathrm{D}$ activities. The solid line represents the government's revenue when the government does not subsidize private $\mathrm{R} \& \mathrm{D}$ activities. It is clear that the revenue is higher in the former than it is the latter if $0<K<2$ and the revenue is higher in the latter than it is in the former if $2<K<8$. Therefore, when $0<K<2$, the government will subsidize private R\&D through subsidies based on the price of the end products, while if $2<K<8$, the government will not subsidize private $R \& D$.

According to the analysis above, in the interval $0<K<2$, the characteristic value of the innovation project is relatively low. Under this circumstance, private innovators are unwilling to implement R\&D activities. Government subsidies can effectively induce innovators to carry out R\&D activities. The subsidy can cause the market to flourish and can increase the innovator's expected revenue. As a result, the revenue of the whole society increases. In the interval $2<K<8$, the characteristic value of the innovation project is relatively high. Private innovators are willing to implement R\&D activities originally. Government subsidies do not increase the number of $R \& D$ activities but do increase the prices that manufacturers charge to end consumers. Thus, the subsidy mainly increases the manufacturer's incomes. The government's revenue therefore decreases.

Proposition 6. The utilization rate of government subsidies decreases with the characteristic value of the innovation project if the government subsidizes private R\&D activities based on the price of the end products.

In Figure 6, the dash-dot line represents the fund utilization rate of the government's subsidy, and the solid line represents the government's revenue. It can be seen that the 
TABLE 2: Outcomes of the game under strategy MP in a monopoly market.

\begin{tabular}{|c|c|c|c|c|c|c|}
\hline$\theta^{M P^{*}}$ & $w^{M P^{*}}$ & $p^{M P^{*}}$ & $\prod_{F}^{M P^{*}}$ & $\prod_{P}^{M P^{*}}$ & $\prod_{G}^{M P^{*}}$ & $\mu^{M P^{*}}$ \\
\hline$\Delta(1+\mu) / 8 \eta-\Delta^{2}$ & $4 \eta(1+\mu) / 8 \eta-\Delta^{2}$ & $6 \eta(\mu+1) / 8 \eta-\Delta^{2}$ & $\eta\left(8 \eta-\Delta^{2}\right) /\left(2 \eta-\Delta^{2}\right)^{2}$ & $4 \eta^{2} /\left(2 \eta-\Delta^{2}\right)^{2}$ & $\eta / 2 \eta-\Delta^{2}$ & $6 \eta / 2 \eta-\Delta^{2}$ \\
\hline
\end{tabular}

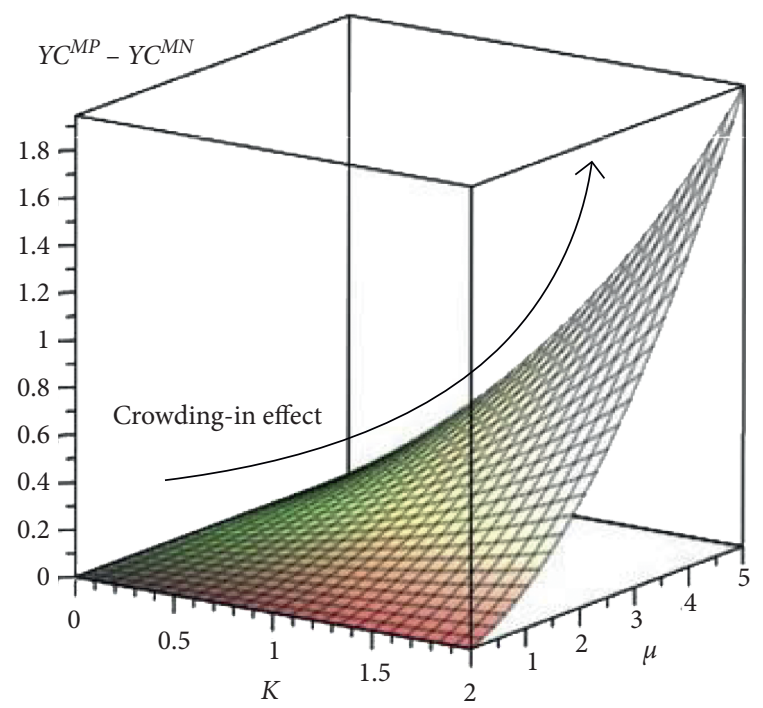

Figure 3: The crowding-in effect of strategy MP in a monopoly market.

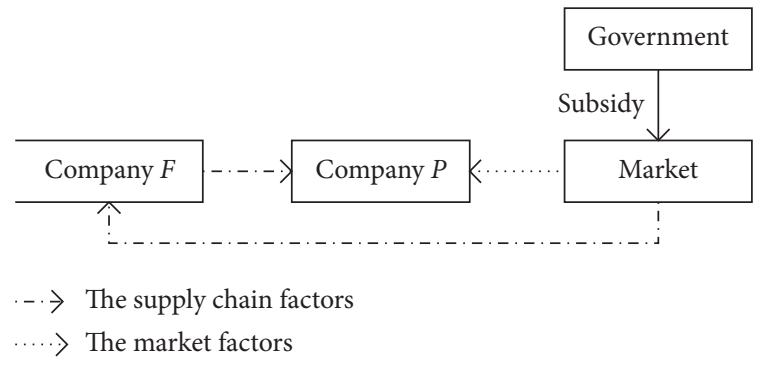

FIgURE 4: The mechanism of strategy MP.

fund utilization rate of the government's subsidy decreases and the government revenue increases with an increase of $K$.

Due to the absence of information on social benefits and costs, prior empirical studies mostly estimated the incremental corporate $\mathrm{R} \& \mathrm{D}$ generated per dollar of $\mathrm{R} \& \mathrm{D}$ subsidies to reveal whether government $\mathrm{R} \& \mathrm{D}$ subsidies "complement" or "take the place of" private R\&D [11]. Our research shows that the fund utilization rate of the government's subsidy is related to the characteristic value of the innovation project. In a monopoly market, the higher the characteristic value of the innovation project is, the higher the fund utilization rate will be.

4.3. Strategy MC. When the government subsidizes $\mathrm{R} \& \mathrm{D}$ based on the innovation cost, the game sequence can be stated as follows:

Step 1: the government decides the subsidy $\tau$, where $\tau \in(0,1)$, according to the information related to the

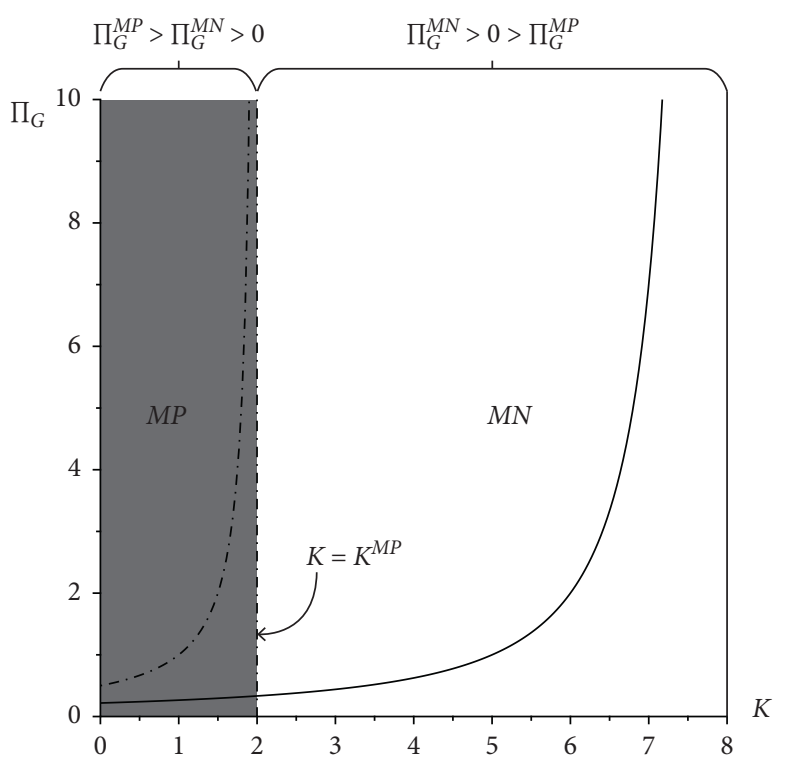

FIGURE 5: Strategy MP in a monopoly market.

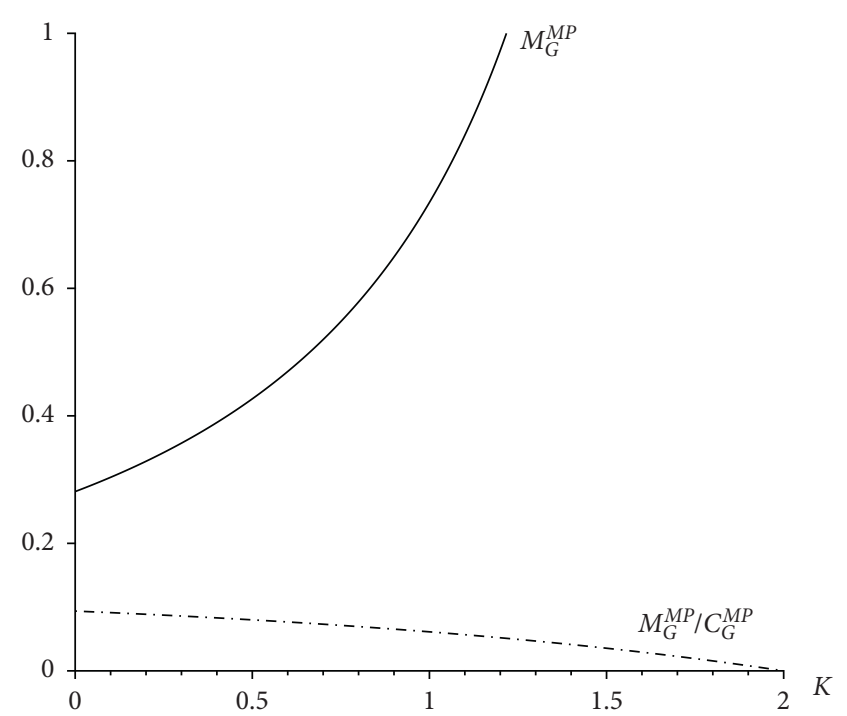

FIgURE 6: The subsidy utilization rate under strategy MP in a monopoly market.

R\&D activities, such as feasibility study reports. Therefore, the innovator's $\mathrm{R} \& \mathrm{D}$ spending is $(1-\tau)\left(c \theta^{2} / \lambda\right)$ and the government subsidy is $\tau\left(c \theta^{2} / \lambda\right)$.

Step 2: the innovator sets the target level of innovation $\theta$ and the price of the new technology $w$.

Step 3: the manufacturer sets the price of the end product $p$. 
Step 4: consumers buy the end product; the innovator, the manufacturer, and the government gain revenue.

The expected profit is denoted as $\prod_{F}^{M C}, \prod_{P}^{M C}$, and $\prod_{G}^{M C}$ for the innovator, the manufacturer, and the government when the government subsidizes R\&D based on the innovation cost, respectively. The $M$ superscript indicates the monopoly market. The $C$ in superscript indicates that the government subsidizes R\&D based on the innovation cost. The profit functions can be written as follows:

$$
\prod_{F}^{M C}=w(1+v r \theta-p)-(1-\tau) \frac{c \theta^{2}}{\lambda}, \prod_{P}^{M C}=(p-w)(1+v r \theta-p), \prod_{G}^{M C}=\prod_{F}^{M C}+\prod_{P}^{M C}+\frac{1}{2}(1+v r \theta-p)^{2}-\tau \frac{c \theta^{2}}{\lambda}
$$

Proposition 7. The outcomes of the game assuming a monopoly market and that the government subsidizes private R\&D based on the innovation cost are shown in Table 3.

Based on the outcomes above, we obtain the following propositions.

Proposition 8. If the government subsidizes private R\&D activities based on the innovation cost, the innovator's optimal target level of innovation and new technology sales price is impacted by the subsidy as follows:

(a) The innovator's optimal target level of innovation increases with the subsidy

(b) The innovator's optimal new technology sale price increases with the subsidy

With a larger subsidy, the optimal target level of innovation will be higher, so the price of the new technology will also be higher. This outcome is consistent with market experience. In fact, when the government chooses to subsidize private $\mathrm{R} \& \mathrm{D}$ activities based on $\mathrm{R} \& \mathrm{D}$ costs, this subsidy will decrease innovators' $\mathrm{R} \& \mathrm{D}$ costs to some extent and thus motivate innovators to set higher innovation goals. With an increase in their target level of innovation, the innovator can charge a higher price for their new technology. This high price will cause the manufacturer to set a higher sales price for the end products. In other words, the subsidy impacts private R\&D through the supply chain, as shown in Figure 7. Comparing this figure with Figure 4, we can see that the two types of subsidies are different in their influence mechanisms.

Proposition 9. In a monopoly market, there are two thresholds $K^{M P}=2$ and $K^{M C}=32 / 7$ such that
(a) $\prod_{G}^{M P^{*}}>\prod_{G}^{M C^{*}}>\prod_{G}^{M N^{*}}$ if $0<K<K^{M P}$
(b) $\prod_{G}^{M C^{*}}>\prod_{G}^{M N^{*}}>0>\prod_{G}^{M P^{*}}$ if $K^{M P}<K<K^{M C}$
(c) $\prod_{G}^{M N^{*}}>0>\prod_{G}^{M C^{*}}$ and $\prod_{G}^{M N^{*}}>0>\prod_{G}^{M P^{*}}$ $K^{M C}<K<8$

Figure 8 depicts the subsidy strategy of governments. The dash-dot line represents the government's subsidization of private $R \& D$ based on the end product price. The dotted line represents the government's subsidization of private $R \& D$ based on the innovation cost. The solid line represents the absence of governmental subsidies of private $\mathrm{R} \& \mathrm{D}$. It can be seen that the optimal government subsidy strategy depends on the characteristic value of the innovation project. When $0<K<2$, the dash-dot line is drawn above the dotted and solid lines, which means that in this situation, the government benefits most by subsidizing private R\&D based on the product price. When $2<K<32 / 7$, the dotted line is drawn above the other lines, which means that in this situation, the government benefits most by subsidizing private R\&D based on the innovation cost. When $32 / 7<K<8$, the solid line is drawn above the other lines, which means that the government will benefit most by providing no subsidy.

Proposition 10. In a monopoly market, if the government subsidizes private ReD based on the innovation cost, the utilization rate of the government's subsidy decreases with an increase in the characteristic value of the innovation project.

In Figure 9, the dotted line represents the utilization rate of government subsidies, and the solid line represents the government's revenue. It can be seen that the utilization rate of the government's subsidy decreases and the government revenue increases with an increase in $K$.

Proposition 11. In a monopoly market, there is a threshold $\tau^{\prime}=-\left(K^{2} / 64\right)+1$ such that a government subsidy crowds in private $R \& D$ investment if $0<\tau<\tau^{\prime}$, and a government subsidy crowds out private R\&D investment if $\tau^{\prime}<\tau<1$.

Private R\&D investment is denoted as $Y C^{M C}$ under the government's cost-dependent subsidy, $Y C^{M C}=(1-\tau) c \theta^{2} /$ $\lambda=K(1-\tau) /[8(1-\tau)-K]^{2}$ and $Y C^{M C}-Y C^{M N}=$ $K \tau\left(64-K^{2}-64 \tau\right) /(K+8 \tau-8)^{2}(K-8)^{2}$. It follows that $Y C^{M C}-Y C^{M N}>0$ if $0<\tau \leq-\left(K^{2} / 64\right)+1$ and $Y C^{M C}-$ $Y C^{M N}<0$ if $-\left(K^{2} / 64\right)+1<\tau<1$. This means that under the cost subsidy, a private innovator invests more in $\mathrm{R} \& \mathrm{D}$ activities if $0<\tau \leq-\left(K^{2} / 64\right)+1$ and a private innovator invests less if $-\left(K^{2} / 64\right)+1<\tau<1$. In other words, the government's subsidy has a crowding-in effect on private $\mathrm{R} \& \mathrm{D}$ investment if $0<\tau \leq-\left(K^{2} / 64\right)+1$ and has a crowding-out effect on private $R \& D$ investment if $-\left(K^{2} / 64\right)+1<\tau<1$. Figure 10 shows the complex influence of government subsidies on private R\&D investment.

Proposition 11 tells us that the government's subsidy is not always better if it is larger. This outcome is in line with some prior studies. Chen et al. analyze data from 269 IT companies in China and find that R\&D subsidies have an 
TABLE 3: Outcomes of the game under strategy MC in a monopoly market.

\begin{tabular}{|c|c|c|c|c|c|c|}
\hline$\theta^{M C^{*}}$ & $w^{M C^{*}}$ & $p^{M C^{*}}$ & $\prod_{F}^{M C^{*}}$ & $\prod_{P}^{M C^{*}}$ & $\prod_{G}^{M C^{*}}$ & $\tau^{M C^{*}}$ \\
\hline$\Delta / 8 \eta(1-\tau)-\Delta^{2}$ & $4 \eta(1-\tau) / 8 \eta(1-\tau)-\Delta^{2}$ & $6 \eta(1-\tau) / 8 \eta(1-\tau)-\Delta^{2}$ & $4 \eta / 32 \eta-7 \Delta^{2}$ & $64 \eta^{2} /\left(32 \eta-7 \Delta^{2}\right)^{2}$ & $7 \eta / 32 \eta-7 \Delta^{2}$ & $3 / 7$ \\
\hline
\end{tabular}

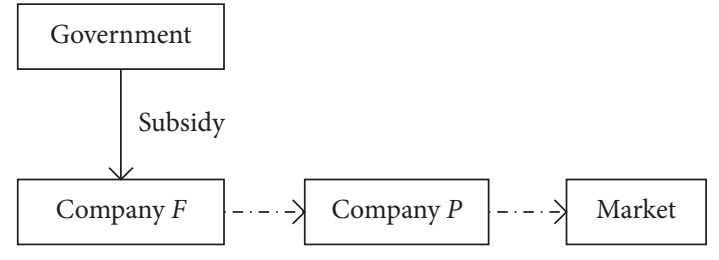

$\cdot \rightarrow$ The supply chain factors

Figure 7: The mechanism of strategy MC.

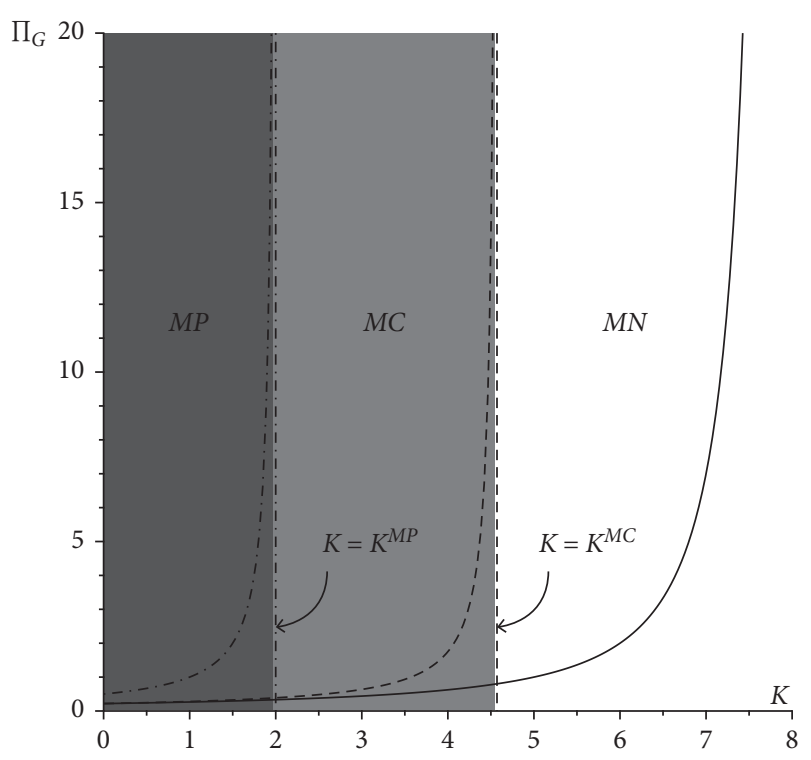

FIGURE 8: Strategies in a monopoly market.

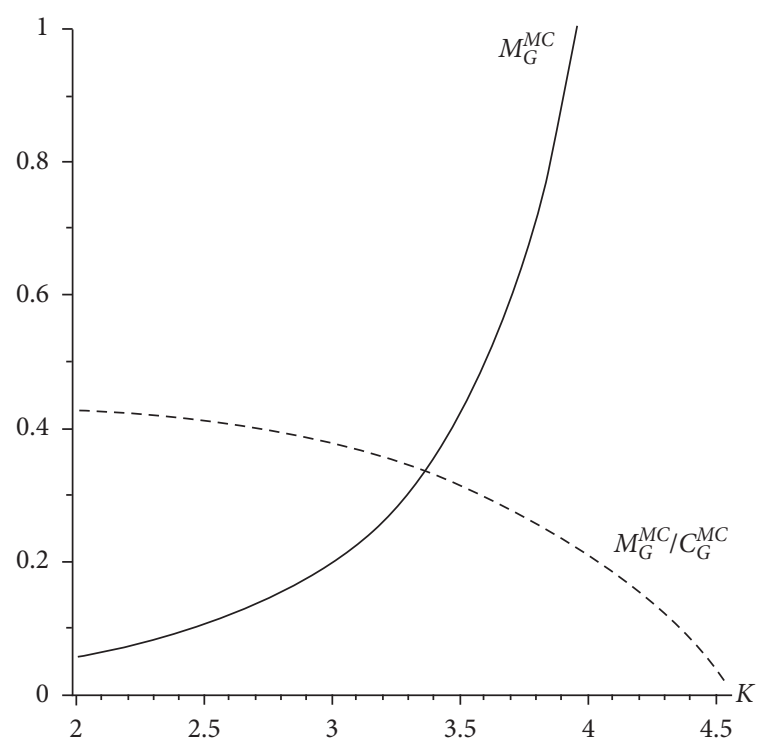

FIgURE 9: The subsidy utilization rate under strategy MC in a monopoly market.

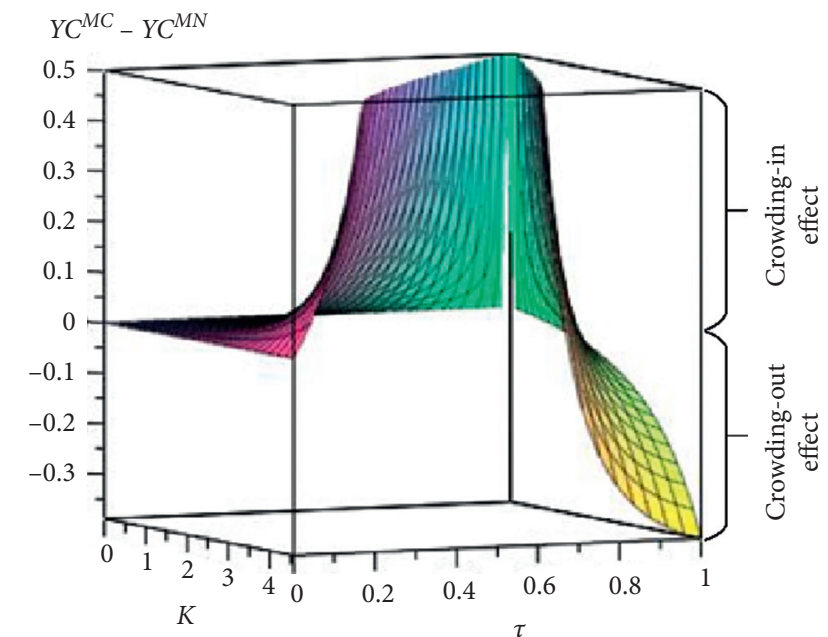

Figure 10: The mixed effect of strategy MC in a monopoly market.

inverted U-shaped effect on private R\&D investment [5]. Dai et al. estimate a dose-response function by using a large sample of Chinese manufacturing firms and find that government subsidies follow an inverted-U correlation with firms' private R\&D investment [43]. In addition, Marino et al. point out that crowding-out effects appear to be stronger under the R\&D tax credit system [18].

In addition, combining Propositions 4 and 11, we conclude that the impact of government subsidies on private $\mathrm{R} \& \mathrm{D}$ investment is affected by the type of subsidy. If governments subsidize private R\&D based on the product price, the subsidy will crowd in private R\&D investment; if governments subsidize private R\&D based on the innovation cost, the subsidy will have an inverted U-shaped effect on R\&D investment.

\section{The Duopoly Market}

In a duopoly market, there is one innovator and two manufacturers in the supply chain. The innovator engages in $\mathrm{R} \& \mathrm{D}$ and sells the resulting new technology to the manufacturers. Both manufacturers integrate the new technology into their products and sell these new products to consumers. The two products are substitutes. Like Section 4, the government has three strategies to incentivize private $\mathrm{R} \& \mathrm{D}$ : (a) no subsidization of R\&D (strategy DN), (b) subsidization of R\&D based on the price of one of the manufacturers' end products (strategy DP), and (c) subsidization of R\&D based on the cost of the R\&D activities (strategy DC), as depicted in Figure 11.

The price and demand of the manufacturer i's product is denoted as $p_{i}$ and $d_{i}$, respectively. The demand function can be written as 


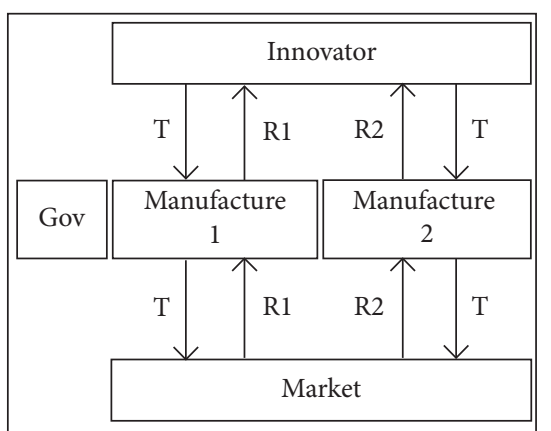

(a)

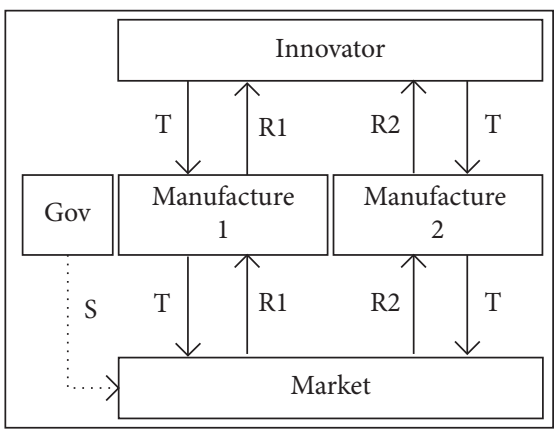

(b)

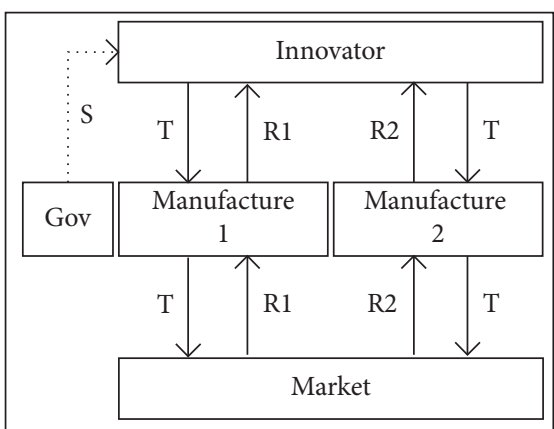

(c)

FIGURE 11: The government's three subsidy strategies in a duopoly market. (a) Strategy DN. (b) Strategy DP. (c) Strategy DC.

$$
d_{i}=1-p_{i}+s\left(p_{3-i}-p_{i}\right)+r \tilde{v} \theta
$$

where $i=1,2$, similarly hereafter. For the innovator, the total demand for new technology is $d=\sum_{i=1}^{2} d_{i}$. The impact of the two products' competition on demand is represented by $s\left(p_{3-i}-p_{i}\right)$ and $s \in(0,1]$, and this impact describes the intensity of competition between the two products. In this paper, we model the demand function in a competitive environment based on the prior research results of Dixit and Singh $[44,45]$. Dixit derives the demand function in the competitive market by modeling the function of consumer surplus. Based on Dixit's research, Singh compares and analyzes the difference between the Cournot model and Bertrand model. Since then, many scholars have applied this model in various competition studies [46-48]. These studies have one thing in common: they use the absolute price to describe the impact of competition on product demand. However, with the development of information technology and e-commerce, it is easy for consumers to compare product prices. Therefore, the absolute price no longer impacts consumers' buying decisions; instead, the relative price has taken its place. As a result, we use $s\left(p_{3-i}-p_{i}\right)$ to represent the impact of the two products' competition on demand. Many other researchers have adopted this approach. For example, Tsay uses the relative price to analyze the distribution problems in the competitive supply chain [49].

5.1. Strategy DS. When the government does not subsidize private $\mathrm{R} \& \mathrm{D}$, the game sequence can be stated as follows:

Step 1: the innovator sets the target level of innovation $\theta$ and the new technology price $w$

Step 2: the two manufacturers set their product prices $p_{1}$ and $p_{2}$ simultaneously

Step 3: consumers buy the end products; the innovator, the manufacturer, and the government gain revenue

The expected profits are denoted as $\prod_{F}^{D N}, \prod_{P_{i}}^{D N}$, and $\prod_{G}^{D N}$ for the innovator, manufacturer $i$, and government, respectively. The $D$ superscript indicates the duopoly market. The $N$ superscript indicates no subsidy. The expected revenue functions can be written as follows:

$$
\prod_{F}^{D N}=\left(2-p_{1}-p_{2}+2 r v \theta\right) w-\frac{c}{\lambda} \theta^{2}, \prod_{P_{i}}^{D N}=\left(p_{i}-w\right)\left[1-p_{i}+s\left(p_{3-i}-p_{i}\right)+r v \theta\right], \prod_{G}^{D N}=\prod_{F}^{D N}+\sum_{i=1}^{2} \prod_{P_{i}}^{D N}+\frac{1}{2}\left(2-p_{1}-p_{2}+2 r v \theta\right)^{2}
$$

The game outcomes are provided in Proposition 12. To ensure the coexistence of the innovator and the manufacturer in the market, $0<K<(2(2+s) / 1+s)$ is required.

Proposition 12. The game outcomes assuming a duopoly market and that the government does not subsidize private ReD are shown in Table 4.

Considering the abovementioned outcomes, we offer the following propositions.

Proposition 13. In a duopoly market, $\theta^{D N^{*}}>\theta^{M N^{*}}$ if $0<K<2(2+s) / 1+s$.
Proposition 13 shows that the competition in a duopoly market encourages the innovator to set a higher target level of R\&D. In other words, the competition between downstream manufacturers will encourage the upstream innovator to pursue a higher innovation goal. Note that $\partial \theta^{D N^{*}} / \partial s=\left(2 \Delta \eta /\left[(s+1) \Delta^{2}-2(s+2) \eta\right]^{2}\right)>0$, and thus, the target innovation level increases with an increase in the intensity of competition.

Proposition 14. In a duopoly market, if the government does not subsidize private R\&D, there is a threshold $K_{p}^{D N}=1$ such that $\partial p_{i}^{D N^{*}} / \partial s>0$ if $0<K<K_{p}^{D N}$ and $\partial p_{i}^{D N^{*}} / \partial s<0$ if $K_{p}^{D N}<K<(2(2+s) / 1+s)$. 
TABLE 4: Outcomes of the game under strategy $\mathrm{DN}$ in a duopoly market.

\begin{tabular}{lccccc}
\hline$\theta^{D N^{*}}$ & $w^{D N^{*}}$ & $p_{i}^{D N^{*}}$ & $\prod_{F}^{D N^{*}}$ & $\prod_{P_{i}}^{D N^{*}}$ & $\prod_{G}^{D N^{*}}$ \\
\hline$(1+s) \Delta / H_{1}$ & $(2+s) \eta / H_{1}$ & $(3+s) \eta / H_{1}$ & $(1+s) \eta / H_{1}$ & $(1+s) \eta^{2} / H_{1}^{2}$ & $4(1+s)(2+s) \eta^{2}-(1+s)^{2} \eta \Delta^{2} / H_{1}^{2}$ \\
\hline
\end{tabular}

Note. $H_{1}=2(2+s) \eta-(1+s) \Delta^{2}$.

Proposition 14 shows that the characteristics of innovation impact the manufacturers' competitive strategies. If the characteristic value of the innovation project is low, the manufacturers have to charge lower prices to increase their product demand and thus increase their revenue. However, if the characteristic value of the innovation project is high, then the manufacturers will charge higher prices to increase their revenue.

In other words, the core conception of Proposition 14 is that low-end technology leads to price wars, while high-end technology leads to value wars. When the characteristic value of the innovation project $K=\Delta^{2} / \eta$ is low, assuming the same $\mathrm{R} \& \mathrm{D}$ cycle cost $\eta$, the economic conversion rate of the technology development $\Delta$ is low; this outcome means, to some extent, that the new technology is low-end technology. According to Proposition 14, manufacturers who apply a low-end technology are likely to be caught in a price war. This situation has already occurred in the Chinese color TV industry. For many years, Chinese color TV enterprises were engaged in a price war which made the color TV industry unprofitable. It is a lack of high-end technology and a high level of competition that causes this terrible situation. According to All View Cloud, a service provider dedicated to providing data analytics for smart homes; although the average price of color TV sets dropped $9.4 \%$ from the previous year in the first half of 2019, the market size did not increase. In the first half of 2019, the retail volume of China's color TV market reached 22 million units, which was down $2.7 \%$ from the previous year, and the retail volume was 64 billion yuan, down $11.8 \%$ from the previous year [50]. The only way to get rid of this price war in the color TV industry is to master high-end technologies.

5.2. Strategy DP. If the government subsidizes $\mathrm{R} \& \mathrm{D}$ by subsidizing one of the manufacturers' products, such as $P_{1}$, with a subsidy $\mu, \mu \in\left(0, p_{1}\right)$, consumers buy manufacturer $P_{1}$ 's products at the price of $p_{1}-\mu$. The demands for the end products of manufacturers 1 and 2 are denoted as $d_{1}$ and $d_{2}$, respectively. Thus, $d_{1}=1-\left(p_{1}-\mu\right)+s\left[p_{2}-\left(p_{1}-\mu\right)\right]+r \tilde{v} \theta$ and $d_{2}=1-p_{2}+s\left[\left(p_{1}-\mu\right)-p_{2}\right]+r \tilde{v} \theta$. The total demand is $d=d_{1}+d_{2}$. The game sequence can be stated as follows:

Step 1: the government sets the subsidy $\mu$

Step 2: the innovator sets the target level of innovation $\theta$ and the price of the new technology $w$

Step 3: the two manufacturers set their product prices $p_{1}$ and $p_{2}$, simultaneously

Step 4: consumers buy the end products; the innovator, the manufacturer, and the government gain revenue

The expected revenues are denoted as $\prod_{F}^{D P}, \prod_{P_{i}}^{D P}$, and $\prod_{G}^{D P}$ for the innovator, manufacturer $i$, and the government, respectively. The $D$ superscript indicates the duopoly market. The $P$ superscript indicates that the government subsidizes R\&D based on the price of the end products. The expected revenue functions can be written as follows:

$$
\begin{aligned}
& \prod_{F}^{D P}=\left(2-p_{1}-p_{2}+2 r v \theta+\mu\right) w-\frac{c}{\lambda} \theta^{2}, \\
& \prod_{P_{1}}^{D P}=\left(p_{1}-w\right)\left[1-\left(p_{1}-\mu\right)+s\left[p_{2}-\left(p_{1}-\mu\right)\right]+r v \theta\right], \\
& \prod_{P_{2}}^{D P}=\left(p_{2}-w\right)\left[1-p_{2}+s\left[\left(p_{1}-\mu\right)-p_{2}\right]+r v \theta\right], \\
& \prod_{F}^{D P}=\prod_{F}^{D P}+\sum_{i=1}^{2} \prod_{P_{i}}^{D P}+\frac{1}{2}\left(2-p_{1}-p_{2}+2 r v \theta+\mu\right)^{2}-\mu d_{1} .
\end{aligned}
$$

Proposition 15. The outcomes of the game assuming a duopoly market and that the government subsidizes private R\&D based on the price of the end products of manufacturer 1 are shown in Table 5 in the appendix.

Comparing Proposition 15 with the previous propositions, we draw the following conclusions.
Proposition 16. In a duopoly market, if the government subsidizes private R\&D based on the price of manufacturer 1 's end product, then $\theta^{D P^{*}}>\theta^{D N^{*}}, \partial \theta^{D P^{*}} / \partial \mu>0$, and $\partial \theta^{D P *^{2}} / \partial \mu \partial s>0$.

It is easy to prove Proposition 16 by calculating $\theta^{D P^{*}}-\theta^{D N^{*}}, \partial \theta^{D P^{*}} / \partial \mu$, and $\partial \theta^{D P *^{2}} / \partial \mu \partial s$. Proposition 16 
TABLE 5: Outcomes of the game under DP in the duopoly market.

\begin{tabular}{lc}
\hline$\theta^{D * *}$ & $(s+1)(\mu+2) \Delta / 4(s+2) \eta-2(s+1) \Delta^{2}$ \\
$w^{D P *}$ & $\eta(s+2)(\mu+2) / 4(s+2) \eta-2(s+1) \Delta^{2}$ \\
$p_{1}^{D P *}$ & {$\left[(7 \mu+6) \eta-2 \mu \Delta^{2}\right] s^{2}+\left[(21 \mu+22) \eta-3 \mu \Delta^{2}\right] s+(10 \mu+12) \eta-\mu \Delta^{2} / 2(3 s+2)\left[2(s+2) \eta-(s+1) \Delta^{2}\right]$} \\
$p_{2}^{D P *}$ & {$\left[(-\mu+6) \eta+2 \mu \Delta^{2}\right] s^{2}+\left[(\mu+22) \eta+3 \mu \Delta^{2}\right] s+(2 \mu+12) \eta+\mu \Delta^{2} / 2(3 s+2)\left[2(s+2) \eta-(s+1) \Delta^{2}\right]$} \\
$\prod_{F}^{D P *}$ & $(s+1)(\mu+2)^{2} / 8(s+2)-4(s+1) K$ \\
$\prod_{P_{1} *}^{D P *}$ & $(s+1)\left[(K-2) 2 \mu s^{2}+(3 \mu K-13 \mu-6) s+\mu K-6 \mu-4\right]^{2} / 4(3 s+2)^{2}[2(s+2)-(1+s) K]^{2}$ \\
$\prod_{P_{2}}^{D P *}$ & $(s+1)\left[(2 \mu K-4 \mu) s^{2}+(3 \mu K-7 \mu+6) s+\mu K-2 \mu+4\right]^{2} / 4(3 s+2)^{2}[2(s+2)-(1+s) K]^{2}$ \\
$\prod_{G *}^{D P}$ & $-\left((s+1)\left[\left(4 s^{4}+14 s^{3}+18 s^{2}+10 s+2\right) \mu^{2} K^{2}+X_{1} K+X_{2}\right] / 4(3 s+2)^{2}[2(s+2)-(1+s) K]^{2}\right)$ \\
$\mu^{D P *}$ & $4 \eta^{2}(s+2)(3 s+2)^{2} /\left(4 s^{4}+14 s^{3}+18 s^{2}+10 s+2\right) K^{2}-\left(16 s^{4}+81 s^{3}+133 s^{2}+88 s+20\right) K+X_{3}$ \\
\hline$N o t e . X_{1}=-16 \mu^{2} s^{4}-81 \mu^{2} s^{3}-133 \mu^{2} s^{2}-88 \mu^{2} s-20 \mu^{2}+36 s^{3}+84 s^{2}+64 s+16 ; X_{2}=\left(16 s^{4}+88 s^{3}+168 s^{2}+128 s+32\right) \mu^{2}-\left(72 s^{3}+240 s^{2}+224 s+64\right) \mu-$
\end{tabular}

shows that, in a duopoly market, a government subsidy that is based on the price of manufacturer 1's product encourages the innovator to set a higher innovation goal. The greater the subsidy is, the higher the goal will be set. Note that $\partial \theta^{D P *^{2}} / \partial \mu \partial s>0$; it follows that the impact of the subsidy on the target level of innovation is influenced by the intensity of market competition. With an increase in the intensity of the competition, this impact becomes stronger.

Proposition 17. In a duopoly market, if the government subsidizes private ReD based on the price of manufacturer 1's end product, then $p_{1}^{D P^{*}}>p_{1}^{D P^{*}}$ and $p_{1}^{D P^{*}}-p_{1}^{D N^{*}}>$ $p_{2}^{D P^{*}}-p_{2}^{D N^{*}}$.

Proposition 17 demonstrates that when the government subsidizes manufacturer $P_{1}$ based on the price of his end product, both manufacturers will charge higher prices. Furthermore, manufacturer $P_{1}$ increases his price more than manufacturer $P_{2}$.

Proposition 18. In a duopoly market, there is a threshold $K^{D P}=16 s^{3}+65 s^{2}+68 s+20-$ $\sqrt{288 s^{5}+1473 s^{4}+2696 s^{3}+2296 s^{2}+928 s+144} / 4\left(2 s^{3}+\right.$ $\left.5 s^{2}+4 s+1\right)$ such that the government subsidizes private R\&D through a subsidy based on the price of manufacturer 1's product iff $0<K<K^{D P}$.

Proposition 18 provides guidance to governments regarding their choice of whether to subsidize using strategy DP in a duopoly market. In the interval $0<K<K^{D P}$, governments should subsidize private $R \& D$ based on the price $p_{1}$; in the interval $K^{D P}<K<(2(s+2) / s+1)$, governments should not subsidize private R\&D activities. Proposition 18 also shows that the competition between manufacturers influences the government's decision-making process regarding subsidy strategy. Recall that in a monopoly market, the interval in which the government should subsidize private $\mathrm{R} \& \mathrm{D}$ activities is $0<K<2$, while in a duopoly market, this interval becomes $0<K<K^{D P}$.

The orange surface in Figure 12 represents the government's revenue after subsidizing private $R \& D$ based on the product price; the blue surface represents the government's revenue without subsidies. It can be seen that in a duopoly market, the orange surface is above the blue surface and increases with an increase in $K$ iff $0<K<K^{D P}$. Figure 13 is the projection of Figure 12 onto the $K-s$ plane and gives a more intuitive picture of the government's subsidy strategy.

Proposition 19. In a duopoly market, if the government subsidizes private R\&D activities based on the price of manufacturer 1's end products, the subsidy has a crowding-in effect on private R\&D investment.

The private $\mathrm{R} \& \mathrm{D}$ investment under strategy $\mathrm{DN}$ and strategy DP in a duopoly market is denoted as $Y C^{D N}$ and $Y C^{D P}$, respectively. According to Propositions 12 and 15, $Y C^{D N}=K(s+1)^{2} /(K s+K-2 s-4)^{2}, \quad Y C^{D P}=K(s+1)^{2}$ $(\mu+2)^{2} / 4(-K s-K+2 s+4)^{2}, \quad$ and $Y C^{D P}-Y C^{D N}=K$ $(s+1)^{2} \mu(\mu+4) /[(-2 K+4) s-2 K+8]^{2}>0$. That is, when the government subsidizes private $R \& D$, the innovator will increase her investment in innovation. Furthermore, note that $\left(\partial\left(Y C^{D P}-Y C^{D N}\right) / \partial s\right)=(K(s+1) \mu(\mu+4) /[2 s+4-$ $\left.(s+1) K]^{3}\right)>0$; it follows that the crowding-in effect becomes stronger with an increase in the intensity of market competition. Figure 14 depicts the crowding-in effect of government subsidies when $s=(1 / 8),(1 / 2),(7 / 8)$.

5.3. Strategy DC. When the government subsidizes R\&D based on the cost of $\mathrm{R} \& \mathrm{D}$, the game sequence can be stated as follows:

Step 1: the government sets the cost subsidy rate $\tau$, where $\tau \in(0,1)$. Therefore, the innovator's R\&D expenditure is $(1-\tau)\left(c \theta^{2} / \lambda\right)$ and the government's subsidy is $\tau\left(c \theta^{2} / \lambda\right)$.

Step 2: the innovator sets the target level of innovation $\theta$ and the sale price of the new technology $w$.

Step 3: the two manufacturers set their prices $p_{1}$ and $p_{2}$, simultaneously.

Step 4: consumers buy the end products; the innovator, the manufacturer, and the government gain revenue.

The expected profits are denoted as $\prod_{F}^{D C}, \prod_{P_{i}}^{D C}$, and $\prod_{G}^{D C}$ for the innovator, manufacturer $i$, and the government, respectively. The $D$ superscript indicates the duopoly market. The $C$ superscript indicates that the government subsidizes R\&D activities based on the innovation cost. The profit functions can be written as follows: 


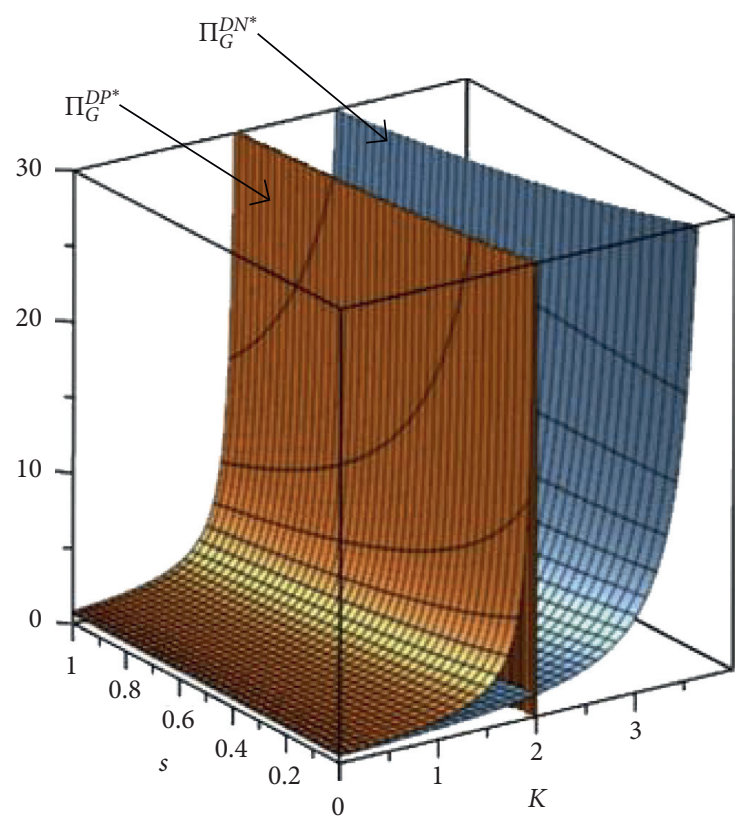

FIGURE 12: Government's revenue under strategies DN and DP in a duopoly market.

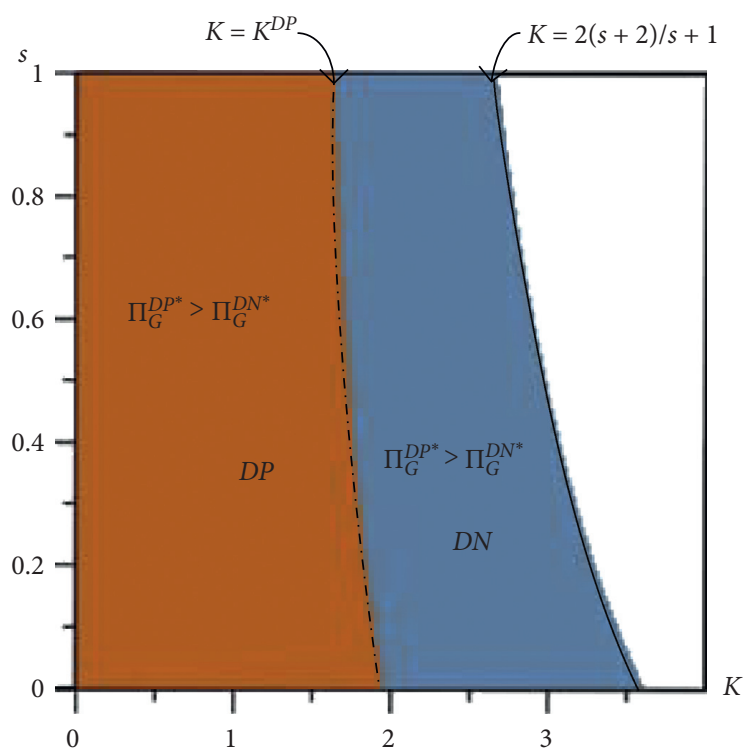

Figure 13: Strategy DP in a duopoly market.

TABLE 6: Outcomes of the game under strategy DC in a duopoly market.

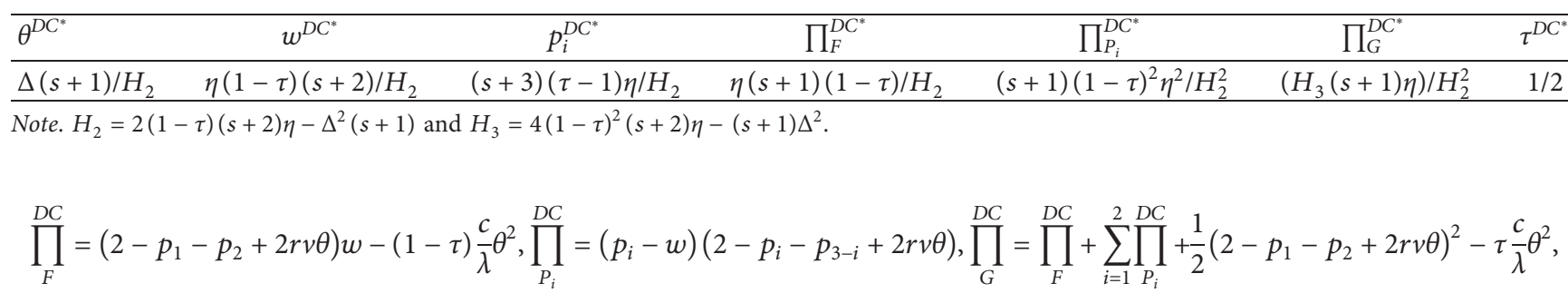




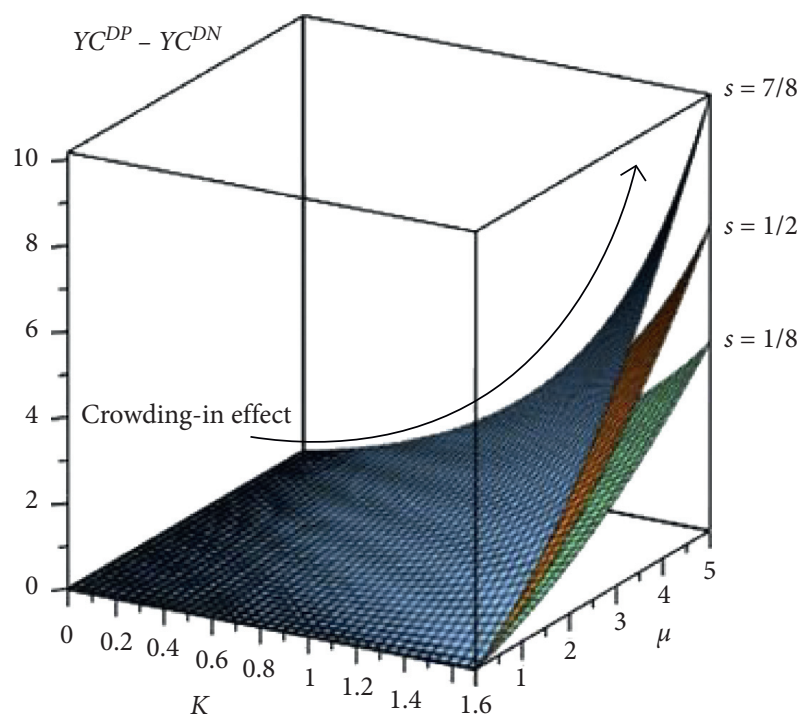

Figure 14: The crowding-in effect of strategy DP in a duopoly market.

Proposition 20. The outcomes of the game assuming a duopoly market and that the government subsidizes private $R \& D$ based on the cost of R\&D are shown in Table 6.

Comparing this with the abovementioned outcomes, we offer the following propositions.

Proposition 21. In a duopoly market, there is a threshold $K^{D C}=s+2 / s+1$ such that the government subsidizes private R\&D based on the cost of R\&D iff $0<K<K^{D C}$.

Proposition 21 provides guidance to the government regarding their choice of whether to subsidize using subsidy strategy DC in a duopoly market. In the interval $0<K<K^{D C}$, governments should subsidize private $\mathrm{R} \& \mathrm{D}$ activities based on the cost of R\&D because, in this interval, $\prod_{G}^{D C^{*}}>\prod_{G}^{D N^{*}}$ which means that cost subsidies will increase the expected revenue of governments. In the interval $K^{D C}<K<2(s+2) / s+1$, governments should not subsidize private $\mathrm{R} \& \mathrm{D}$ in this way because, under this circumstance, $\prod_{G}^{D C^{*}}<\prod_{G}^{D N^{*}}$ which means that cost subsidies will decrease the governments' expected revenue. Proposition 21 also shows that market competition influences the governments' decision-making process regarding subsidy strategy. In a monopoly market, the interval in which governments should subsidize private $\mathrm{R} \& \mathrm{D}$ activities is $0<K<2$, while in a duopoly market, this interval becomes $0<K<K^{D C}$.

By adopting the analytical method suggested in Proposition 18, we draw the projection diagram shown in Figure 15. The green area represents the governments' expected revenue and shows that this revenue is higher under strategy $\mathrm{DC}$ than that under strategy DN. Thus, if there are private $\mathrm{R} \& \mathrm{D}$ activities in this area, it is advisable for governments to subsidize $R \& D$ based on $R \& D$ cost. The blue area represents the government's revenue and shows that this revenue is higher under strategy DN than that under strategy DC. Thus,

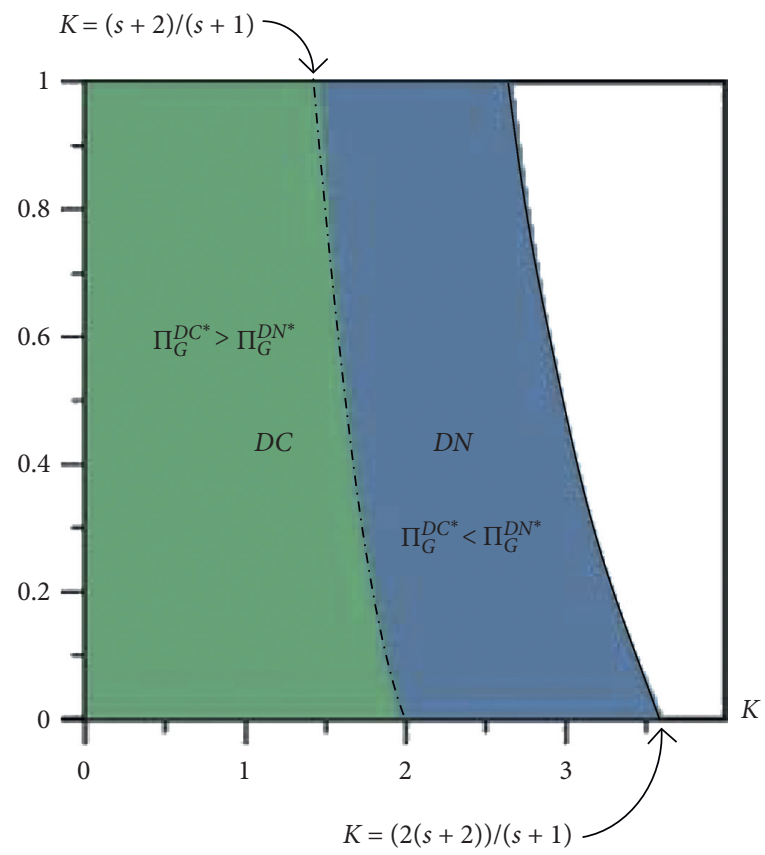

FIGURE 15: Strategy DC in a duopoly market.

if there are private $R \& D$ activities in this area, it is advisable for governments not to subsidize R\&D in this way.

Based on the above analysis, we draw a comprehensive conclusion as follows.

Proposition 22. In a duopoly market, there are three thresholds: $\quad K^{D C}=s+2 / s+1, \quad K^{D P}=16 s^{3}+65 s^{2}+68 s+$ $20-\sqrt{288 s^{5}+1473 s^{4}+2696 s^{3}+2296 s^{2}+928 s+144} / 4\left(2 s^{3}\right.$ $\left.+5 s^{2}+4 s+1\right)$, and $K^{D P C}=(1 / 2)\left(4 s^{4}+9 s^{3}+7 s^{2}+2 s /\right.$ $\left.(s+1)^{3}(1+2 s)\right)$ for the economic conversion rate and ReD cycle cost ratio such that

(a) $\prod_{G}^{D N^{*}}>\prod_{G}^{D C *}$ and $\prod_{G}^{D N^{*}}>\prod_{G}^{D P^{*}}$ if $K^{D P}<K<$ $(2(2+s) / 1+s)$

(b) $\prod_{G}^{D P^{*}}>\prod_{G}^{D C *}$ and $\prod_{G}^{D P^{*}}>\prod_{G}^{D N^{*}}$ if $K^{D C}<K<K^{D P}$ or $0<K<K^{D P C}$

(c) $\prod_{G}^{D C *}>\prod_{G}^{D P^{*}}$ and $\prod_{G}^{D C *}>\prod_{G}^{D N^{*}}$ if $K^{D P C}<$ $K<K^{D C}$

Proposition 22 demonstrates the comprehensive government subsidy strategy in a duopoly market. Figure 16 depicts a projection of the graph of the government's revenues. The blue area represents situations in which governments should not subsidize private $R \& D$; the orange area represents situations in which governments should subsidize private $R \& D$ based on the price of the end products of the manufacturers, and the green area represents situations in which governments should subsidize private R\&D based on the cost of R\&D.

Proposition 23. In a duopoly market, if the government subsidizes private R\&D based on the cost of R\&D, there is a threshold $\tau^{\prime \prime}=-\left(K^{2}(s+1)^{2} / 4(s+2)^{2}\right)+1$ such that the 


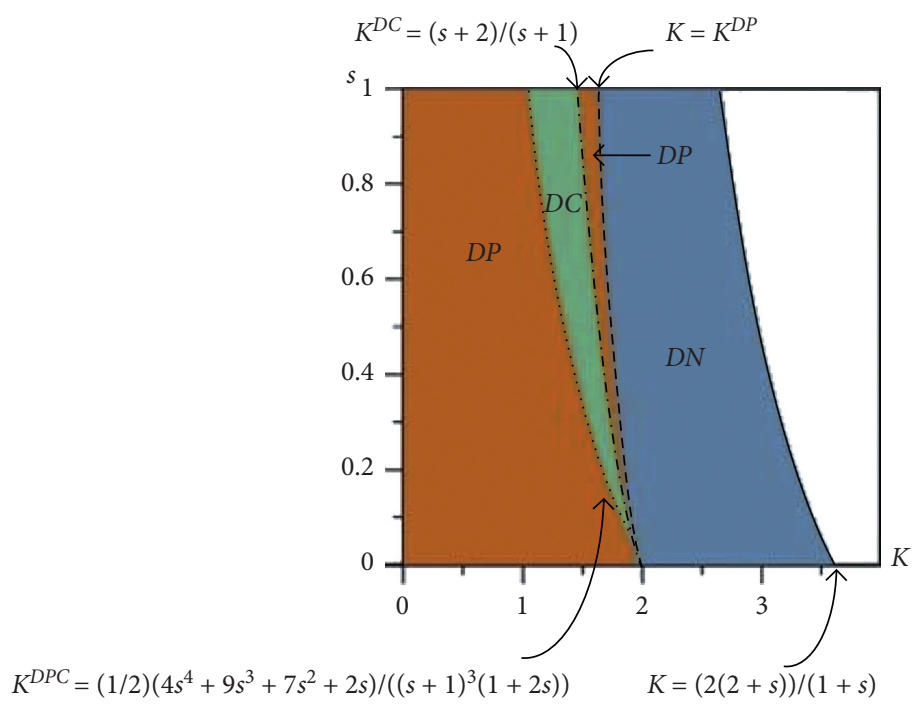

FIGURE 16: Subsidy strategies in a duopoly market.

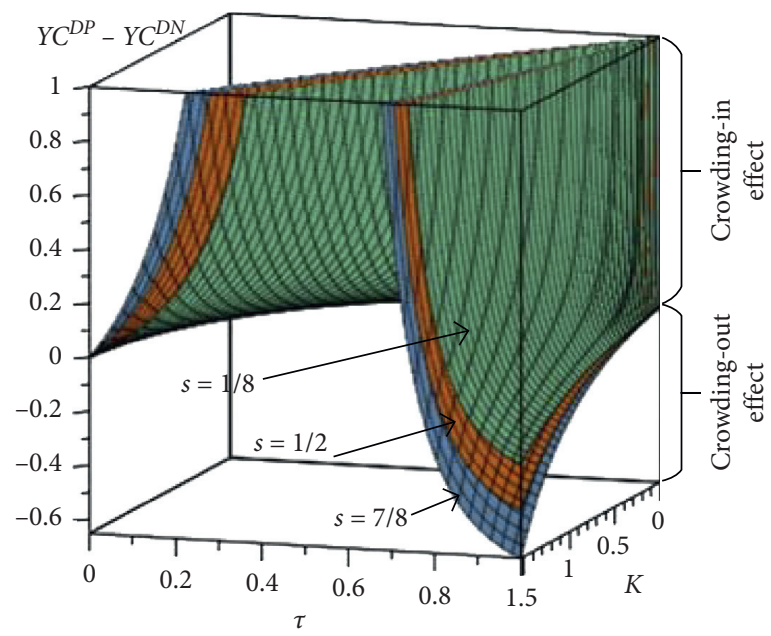

FIGURE 17: The mixed impact of government subsidies under strategy $D C$ in a duopoly market.

government subsidies crowd in private R\&D investment if $0<\tau<\tau^{\prime \prime}$ and crowd out private investment if $\tau^{\prime \prime}<\tau<1$.

Proposition 23 shows that, in a duopoly market, different amounts of government subsidies impact incentive results differently. When the amount of the government subsidies is comparatively low $\left(0<\tau<\tau^{\prime \prime}\right)$, private investment in $\mathrm{R} \& \mathrm{D}$ will increase with the amount of the subsidies. However, once the amount of the subsidies exceeds this threshold, private investment in $\mathrm{R} \& \mathrm{D}$ will decrease with the amount of subsidy. The former is called the crowd-in effect of government subsidies, and the latter is called the crowd-out effect of government subsidies.

Figure 17 depicts the mixed impact of government subsidies on private investment when $s=(1 / 8),(1 / 2)$, and $(7 / 8)$.

\section{Empirical Analysis}

In this section, we use panel data from China's A-share market to verify and analyze the conclusion that government subsidies have both crowding-in and out effects on enterprise R\&D investment.

6.1. Data and Variable Definitions. Our data were acquired mainly from three sources: the Wind database, the Shanghai stock exchange, and the Shenzhen stock exchange. Basic information was obtained from the Wind database (https:// www.wind.com.cn). From the Wind database, we obtained the panel data of 3,815 listed companies in China's A-share market from the years 2013 to 2019. After sorting the data, 
TABLE 7: Descriptive statistics of the variables.

\begin{tabular}{lccccccc}
\hline Variable & Mean & Min & Max & Variable & Mean & Min & Max \\
\hline R\&D & 17.71434 & 10.17615 & 21.74779 & Ratio & 40.40812 & 5.2066 \\
Sub & 16.11784 & 9.903488 & 20.70653 & Roa & 11.93426 & -112.6857 \\
Sub $^{2}$ & 261.8726 & 98.07907 & 428.7606 & Age & 16.70627 & 460.7378 \\
Size & 21.79704 & 18.937 & 27.10614 & Own & .2783278 & 3 & 0 \\
\hline
\end{tabular}

TABLE 8: Regression analysis results.

\begin{tabular}{lccc}
\hline R\&D & Coef. & Std. err. & $P>|t|$ \\
\hline Sub & 1.116698 & 0.3045695 & 0.000 \\
Sub $^{2}$ & -0.0284379 & 0.0096647 & 0.003 \\
Size & 0.6542147 & 0.0394157 & 0.000 \\
Ratio & -0.0079545 & 0.001997 & 0.000 \\
Roa & 0.0066098 & 0.0016801 & 0.000 \\
Age & -0.0184702 & 0.0064207 & 0.004 \\
Own & -0.3278941 & 0.0806138 & 0.000 \\
Cons & -6.454882 & 2.643822 & 0.015 \\
Number of obs & 909 & $F(7,901)$ & 116.16 \\
Prob $>F$ & 0.0000 & $R^{2}$ & 0.4744 \\
Root MSE & 1.029 & $\mathrm{Adj}-R^{2}$ & 0.4703 \\
\hline
\end{tabular}

we found that the data of some listed companies were missing. Therefore, we searched the annual reports of the listed companies with missing data using the official websites of the Shanghai stock exchange and the Shenzhen stock exchange, supplemented the missing data with the information we obtained and deleted the blank data that we were unable to find. Then, we screened the data and eliminated the enterprises having no R\&D expenditures, no government subsidies, and no government tax refunds. The final sample size was 909 .

To verify the conclusion of the above analysis, namely, that government subsidies for innovation activities have both crowding-out and crowding-in effects on private $R \& D$ investment, we combined the empirical research of the relevant literature $[18,43,51]$ and selected 7 indicators to establish the econometric model. The 7 indicators were enterprise $\mathrm{R} \& \mathrm{D}$ investment, government $\mathrm{R} \& \mathrm{D}$ subsidies, enterprise total assets, asset to liability ratio, return on net assets, the age of the enterprise, and whether the enterprise is a state-owned enterprise. The model can be written as follows:

$$
\mathrm{R} \& \mathrm{D}=\beta_{0}+\beta_{1} \mathrm{sub}+\beta_{2} \mathrm{sub}^{2}+\beta_{3} \text { size }+\beta_{4} \text { ratio }+\beta_{5} \text { roa }+\beta_{6} \text { age }+\beta_{7} \text { own }+\varepsilon,
$$

where $R \& D$ represents the natural logarithm of the total R\&D expenditure of the enterprise; sub represents the natural logarithm of the governmental R\&D subsidies; sub ${ }^{2}$ represents the second power of the sub; size is the natural logarithm of the total assets of the enterprise, which measures the size of the enterprise; ratio denotes the ratio of assets to liabilities; roa represents the rate of return on net assets; age describes when the company was founded; own is a dummy variable with state-owned enterprises denoted as 1 and nonstate-owned enterprises denoted as 0 ; and $\varepsilon$ is the error term. According to the previous theoretical analysis, if the government $\mathrm{R} \& \mathrm{D}$ subsidies have both a crowding-out and in effect on total R\&D expenditure, then $\beta_{2}<0$. The descriptive statistics of each variable in the model are shown in Table 7.

6.2. Regression Analysis. Based on equation (13), we empirically tested the impact of governmental R\&D subsidies on private $\mathrm{R} \& \mathrm{D}$ investment, and the regression results obtained from this analysis are shown in Table 8 .

As shown in Table 8, the coefficient of government R\&D subsidies (sub) as an explanatory variable is 1.116698, and the coefficient of its square term is -0.0284379 . Combined with equation (13), after controlling the variable size, ratio, roa, and own, R\&D is a quadratic function of sub. The quadratic function is a convex function, showing an inverted $\mathrm{U}$ shape. There is an optimal amount for governmental subsidies $\tau^{*}$. When the subsidy amount is less than the optimal subsidy amount $\tau^{*}$, private $\mathrm{R} \& \mathrm{D}$ investment increases with an increase in the subsidy amount, and the subsidy has a crowding-in effect on private investment. When the amount of the subsidy exceeds the optimal amount, private $\mathrm{R} \& \mathrm{D}$ investment will decrease with an increase in the subsidy amount, and the subsidy has a crowding-out effect on private investment. The conclusion of this empirical study is consistent with the conclusions of the theoretical analysis of this paper.

\section{Concluding Remarks}

In this paper, six game-theoretic models are developed to analyze governmental subsidy strategies in different market environments and to investigate the problem of whether government subsidies crowd in or crowd out private investment in R\&D activities. Based on realistic situations, we classify government subsidies into three types, namely, no subsidy provided, subsidy provided based on the price of the end products, and subsidy provided based on the cost of R\&D. In addition, according to whether competition exists in the market, we classify markets into monopoly markets and duopoly markets.

First, we note the two factors that should be considered during the government's decision-making process regarding subsidy strategy. The first factor is the characteristic value of 
the innovation project. If the characteristic value is relatively low, then subsidizing private R\&D based on the price of the end product is advisable for the government. If the characteristic value is high, then subsidizing private $R \& D$ based on the cost of $\mathrm{R} \& \mathrm{D}$ is advisable for the government. If the characteristic value is extremely high, then no subsidization of private $\mathrm{R} \& \mathrm{D}$ is advisable for the government. For example, the subsidies provided to the new-energy automobile industry in mainland China by the government vary with market profitability, which is mainly reflected in our measure of characteristic value. When new energy vehicles first entered the Chinese market, consumers had many concerns about these new products, including battery life, charging, and after-sales maintenance. These concerns led to almost no market demand for new energy vehicles at that time. For the sake of environmental protection and technological development, the Chinese government issued the "notice on the demonstration and promotion of the pilot work of energy-saving and new energy vehicles" on January 23, 2009. This notice stated that, to support the industrialization of new energy vehicles, a financial subsidy program of 10 billion yuan would be implemented. Part of the subsidy would be given to consumers who bought the new energy vehicles directly. The subsidies have encouraged a good market response, and the number of users who buy new energy vehicles has been increasing each year. After the development of the consumer market, the subsidy provided by the Chinese government to the new energy automobile industry shifted from consumers to innovators. On April 22, 2015, the government issued the "notice regarding 2016-2020, the financial support policy on new energy automobile application". This notice states that during the years $2017-18$, subsidies would be $20 \%$ less than they were in 2016, and during the years 2019-20, subsidies would be $40 \%$ less than they had been in 2016. On December 29, 2016, the government issued the "adjustment of new energy automobile application fiscal subsidy policy notice," stating that battery development would be the target of the subsequent subsidies provided for new energy vehicles. It can be seen that the subsidy policy of the Chinese government in relation to the new energy automobile industry is nearly consistent with the research conclusions of this paper.

The second factor that should be considered is the market environment. The intensity level of competition can influence the decision-making process to some extent.

Our second main conclusion shows that, for private $R \& D$, governmental subsidies are not always better if they are larger. For different R\&D activities, there is an optimal subsidy amount for each type of subsidy. For example, our research notes that, in a monopoly market, if the government subsidizes private $\mathrm{R} \& \mathrm{D}$ based on the cost of $\mathrm{R} \& \mathrm{D}$, the optimal proportion for the subsidy is $3 / 7$, while in a duopoly market, if the government chooses the same type of subsidy, the optimal proportion is $1 / 2$.

We also discuss the impact of governmental subsidies on private investment in $\mathrm{R} \& \mathrm{D}$. According to our analysis, if governments subsidize private $R \& D$ based on the price of the end products, the subsidy will crowd private R\&D investment in. However, if governments subsidize private
$R \& D$ based on the cost of $R \& D$, there will be an inverse $\mathrm{U}$-shaped relationship between the amount of the subsidy and private investment. The competition between manufacturers does not have a material impact in this case, but the stronger the intensity of competition is, the more significantly the subsidy will impact private investment.

There are several future research directions. First, we have assumed that competition mainly occurs between manufacturers. In reality, competition is more complex. It may occur between innovators, and it may occur between innovators and manufacturers. Furthermore, it would be interesting to consider the influences of bounded rationality such as overconfidence and fairness preference. We reserve these topics for future study.

\section{Appendix}

Proof of Proposition 1. We provide only the proof process of no subsidy in the monopoly market. Due to space limitations, we omit the detailed proofs for the other five models' outcomes (the proofs are similar and straightforward).

According to backward induction, we fist maximize the profit function (5) and obtain the best response function $p^{M N}(\theta, w)=(1 / 2)(r v \theta+w+1)$.

We then substitute it into the innovator's profit function and have

$$
\prod_{F}^{M N}=\frac{1}{2} \frac{w(r v \theta-w+1) \lambda-2 c \theta^{2}}{\lambda} .
$$

We maximize the innovator's profit function in $\theta$ and $w$ simultaneously, and solving them simultaneously yields

$$
\begin{aligned}
\theta^{M N^{*}} & =\frac{r v \lambda}{8 c-r^{2} v^{2} \lambda} ; \\
w^{M N^{*}} & =\frac{4 c}{8 c-r^{2} v^{2} \lambda} .
\end{aligned}
$$

Substituting them into the response function $p^{M N}$ $(\theta, w)=1 / 2(r v \theta+w+1)$, we can get

$$
p^{M N^{*}}=\frac{6 c}{8 c-r^{2} v^{2} \lambda} \text {. }
$$

Substituting $\theta^{M N^{*}}=(r v \lambda) /\left(8 c-r^{2} v^{2} \lambda\right), w^{M N^{*}}=(4 c) /$ $\left(8 c-r^{2} v^{2} \lambda\right)$, and $p^{M N^{*}}=(6 c) /\left(8 c-r^{2} v^{2} \lambda\right)$ in (4), (5), and (6), we can get

$$
\prod_{F}^{M N^{*}}=\frac{\eta}{8 \eta-\Delta^{2}}, \prod_{P}^{M N^{*}}=\frac{4 \eta^{2}}{\left(8 \eta-\Delta^{2}\right)^{2}}, \prod_{G}^{M N^{*}}=\frac{\eta\left(14 \eta-\Delta^{2}\right)}{\left(8 \eta-\Delta^{2}\right)^{2}} .
$$

Proof of Proposition 2. The proof process is the same with Proposition 1.

Proof of Proposition 3. The proposition can be deduced from the functions of $\theta^{M P^{*}}$ and $w^{M P^{*}}$. 
Proof of Proposition 5. Denote $M_{G}^{M P}$ as the added value of the government's revenue under the situation of SP, and $M_{G}^{M P}=\prod_{G}^{M P^{*}}-\prod_{G}^{M P^{*}}=36 /(2-K)(8-K)^{2}$. It is clear that $M_{G}^{N R}>0$ if $0<K<2$ and $M_{G}^{N R}<0$ if $2<K<8$.

Proof of Proposition 6. Denote $C_{G}^{M P}$ as the total spending when the government subsidizes the private $R \& D$ activities depending on the price of the end product. $C_{G}^{M P}=\mu d=12 /(2-K)^{2}$. According to Proposition 5, the added government's revenue is $M_{G}^{M P}=36 /(2-K)(8-K)^{2}$. So, the fund utilization rate of the government's subsidy is $M_{G}^{M P} / C_{G}^{M P}=3(2-K) /(8-K)^{2}$. It decreases with $K$.

Proof of Proposition 7. The proof process is the same with Proposition 1.

Proof of Proposition 8. The proposition can be deduced from the functions of $\theta^{M C^{*}}$ and $w^{M C^{*}}$ easily.

Proof of Proposition 9. Denote $M_{G}^{M C}$ as the added value of the government's revenue under the situation of SC, and then $M_{G}^{M C}=\prod_{G}^{M C^{*}}-\prod_{G}^{M N^{*}}=18 K /(32-7 K)(8-K)^{2}$. Obviously, $\quad M_{G}^{M C}>0$ if $0<K<32 / 7$ and $M_{G}^{M C}<0$ if $32 / 7<K<8$. Combining with Proposition 5 , we can easily prove Proposition 9.

Proof of Proposition 10. Denote $C_{G}^{M C}$ as the total spending when the government subsidizes the private R\&D activities depending on the cost of R\&D. $C_{G}^{M C}=(3 / 7)(c / \lambda) \theta^{2}=21 K /(32-7 K)^{2}$. According to Proposition $9, M_{G}^{M C}=18 K /(32-7 K)(8-K)^{2}$. So, the utilization rate of the government's subsidy is $M_{G}^{M C} / C_{G}^{M C}=6(32-7 K)^{2} /(32-7 K)(8-K)^{2}$. It can be proved easily that if $2<K<32 / 7, M_{G}^{M C} / C_{G}^{M C}$ decreases with the value of $K$.

Proof of Proposition 11. For the convenience of understanding, we leave the proof of this conclusion in the text.

Proof of Proposition 12. The proof is the same as Proposition 1.
Proof of Proposition 13. Due to $\theta^{D N^{*}}-\theta^{M N^{*}}=(6 s+4)$ $\Delta \eta /\left[2 \eta(s+2)-(s+1) \Delta^{2}\right]\left(8 \eta-\Delta^{2}\right)$, it is easy to prove that if $0<\Delta^{2} / \eta<2(2+s) / 1+s$, then $\theta^{D N^{*}}-\theta^{M N^{*}}>0$.

Proof of Proposition 14. Because $p_{i}^{D N^{*}}=(3+s) \eta / 2(2+$ $s) \eta-(1+s) \Delta^{2}$, thus $\partial p_{i}^{D N^{*}} / \partial s=2 \eta\left(\Delta^{2}-\eta\right) /\left(\Delta^{2} s+\Delta^{2}-\right.$ $2 \eta s-4 \eta)^{2}$. It is easy to see that if $0<K=\Delta^{2} / \eta<1$, then $\partial p_{i}^{D N^{*}} / \partial s>0$; if $\quad 1<K=\Delta^{2} / \eta<2(2+s) / 1+s$, then $\partial p_{i}^{D N^{*}} / \partial s<0$.

Proof of Proposition 15. The proof process is the same with Proposition 1, and the outcomes are shown in Table 5.

Proof of Proposition 16. According to Propositions 4 and 15, $\theta^{D P^{*}}-\theta^{D N^{*}}=(s+1) \mu \Delta /(-2 s-2) \Delta^{2}+4 \eta(s+2)$; because $0<\Delta^{2} / \eta<2(2+s) / 1+s$, thus $\theta^{D P^{*}}-\theta^{D N^{*}}>0$.

In addition, $\quad \partial \theta^{D P^{*}} / \partial \mu=(s+1) \Delta /(-2 s-2) \Delta^{2}+4$ $(s+2) \eta>0 ; \quad \partial \theta^{D P *^{2}} / \partial \mu \partial s=(s+1) \mu \Delta /(-2 s-2) \Delta^{2}+4(s+$ 2) $\eta>0$.

Proof of Proposition 17. Because $0<\Delta^{2} / \eta<2(2+s) / 1+s$, thus

$$
p_{1}^{D P^{*}}-p_{1}^{D N^{*}}=\frac{1}{2} \frac{\mu(s+1)\left(\Delta^{2}-3 \eta s-10 \eta\right)}{(3 s+2)\left(\Delta^{2} s+\Delta^{2}-2 \eta s-4 \eta\right)}>0 .
$$

In the same way, we can prove $p_{1}^{D P^{*}}-$ $p_{1}^{D N^{*}}>p_{2}^{D P^{*}}-p_{2}^{D N^{*}}$.

Proof of Proposition 18. According to the foregoing Propositions 14 and 11,

$$
\prod_{G}^{D P^{*}}-\prod_{G}^{D N^{*}}=\frac{(3 s+2)^{2}(s+2)^{2}}{16 f_{1}(K)[(-(1 / 2) K+1) s-(1 / 2) K+2]^{2}}
$$

where $f_{1}(K)=(-(1 / 2) K+1)^{2} s^{3}+\left((5 / 8) K^{2}-(65 / 16) K+(9 /\right.$ $2)) s^{2}+\left((1 / 2) K^{2}-(17 / 4) K+6\right) s+(1 / 8) K^{2}-(5 / 4) K+2$.

Solving the function $f_{1}(K)=0$, we can get

$$
\begin{aligned}
& K_{1}=\frac{16 s^{3}+65 s^{2}+68 s+20-\sqrt{288 s^{5}+1473 s^{4}+2696 s^{3}+2296 s^{2}+928 s+144}}{4\left(2 s^{3}+5 s^{2}+4 s+1\right)} \\
& K_{2}=\frac{16 s^{3}+65 s^{2}+68 s+20+\sqrt{288 s^{5}+1473 s^{4}+2696 s^{3}+2296 s^{2}+928 s+144}}{4\left(2 s^{3}+5 s^{2}+4 s+1\right)}
\end{aligned}
$$

Because $0<K<2(2+s) / 1+s$, we can conclude as follows:

$$
\begin{aligned}
& \text { If } 0<K<K^{D P} \text {, then } \prod_{G}^{D P^{*}}>\prod_{G}^{D N^{*}} \text {. } \\
& \text { If } K^{D P}<K<2(s+2) / s+1 \text {, then } \prod_{G}^{D P^{*}}<\prod_{G}^{D N^{*}} .
\end{aligned}
$$

Proof of Proposition 19. For the convenience of understanding, we leave the proof of this conclusion in the text.

Proof of Proposition 20. The proof process is the same with Proposition 1. 
Proof of Proposition 21. According to Proposition 19, if the government chooses the subsidy $\tau^{D C *}=1 / 2$, then $\prod_{G}^{D C *}=(s+1) /(s+2)-(s+1) K$, and $\prod_{G}^{D C *}-\prod_{G}^{D N^{*}}=$ $(1 / 4)\left((s+2)(s+1)^{2} K /[(1-K) s+(2-K)][(1-(1 / 2) K)\right.$ $\left.s+(2-(1 / 2) K)]^{2}\right)$. Thus, if $0<K<s+2 / s+1$, then $\prod_{G C *}^{D C *}-\prod_{G N^{*}}^{D N^{*}}>0$; if $s+2 / s+1<K<2(2+s) / 1+s$, then
$\prod_{G}^{D C *}-\prod_{G}^{D N^{*}}<0$.

Proof of Proposition 22. The thresholds $K^{D C}$ and $K^{D P}$ have already been proved in Propositions 17 and 20. In the same way, we can prove the existence of $K^{D P C}$. We omit the details here.

Proof of Proposition 23. Denote $Y C^{D C}$ as the private R\&D investment under the government's cost subsidy in the duopoly market. According to Proposition 19, $Y C^{D C}=$ $(1-\tau)(s+1)^{2} K /[(s+1) K-2(1-\tau)(s+2)]^{2}, \quad$ and $Y C^{D C}$ $-Y C^{D N}=\left[4(1-\tau)(s+2)^{2}-(s+1)^{2} K\right](s+1)^{2} \tau K /[(s+1) K$ $-2(1-\tau)(s+2)]^{2}[2(s+2)-(s+1) K]^{2}$. It follows that $Y C^{D C}-Y C^{D N} \geq 0$ if $0<\tau \leq-\left(K^{2}(s+1)^{2} / 4(s+2)^{2}\right)+1$, and $Y C^{D C}-Y C^{D N}<0$ if $-\left(K^{2}(s+1)^{2} / 4(s+2)^{2}\right)+1<\tau<1$. The proof is completed.

\section{Data Availability}

All data, models, and codes generated or used during the study are included within the article.

\section{Conflicts of Interest}

The authors declare that they have no conflicts of interest.

\section{References}

[1] K. Arrow, Economic Welfare and the Allocation of Resources for Invention, Palgrave, London, UK, 1972.

[2] C. Yang, Chengdu: Major Scientific and Technological Innovation Carried Out Around 5G Will Get a Maximum Subsidy of 2 Million Yuan, Chengdu Daily, Chengdu, China, 2019.

[3] R. Ordos, "Ordos promotes science and technology to innovate again,” 2019, http://www.ordos.gov.cn/sq_127930/ zsyz/tzzc/201904/t20190409_2353221.html.

[4] R. G. W. Fiddian-GreenZhang and W. W. SilenHuang, "Mechanisms of disposal of acid and alkali in rabbit duodenum," The American Journal of Physiology, vol. 229, no. 6, pp. 1641-1648, 1975.

[5] J. Chen, C. S. C. S. Heng, B. C. Y. B. C. Y. Tan, and Z. Linau, "The distinct signaling effects of R\&D subsidy and non-R\&D subsidy on IPO performance of IT entrepreneurial firms in China," Research Policy, vol. 47, no. 1, pp. 108-120, 2018.

[6] E. Z. E. Z. Demirci and N. K. N. K. Erkip, "Designing an intervention strategy for public-interest goods: the California electric vehicle market case," Omega, vol. 69, pp. 53-69, 2017.

[7] S. Alizamir, F. de Véricourt, and P. Sun, "Efficient feed-intariff policies for renewable energy technologies," Operations Research, vol. 64, no. 1, pp. 52-66, 2016.

[8] V. Abhishek, K. Jerath, and Z. J. Z. J. Zhang, "Agency selling or reselling? Channel structures in electronic retailing," Management Science, vol. 62, no. 8, pp. 2259-2280, 2016.

[9] G. Raz and A. Ovchinnikov, "Coordinating pricing and supply of public interest goods using government rebates and subsidies," IEEE Transactions on Engineering Management, vol. 62, no. 1, pp. 65-79, 2015.

[10] C. Dimos and G. Pugh, "The effectiveness of R\&D subsidies: a meta-regression analysis of the evaluation literature," Research Policy, vol. 45, no. 4, pp. 797-815, 2016.

[11] J. Choi and J. Lee, "Repairing the R\&D market failure: public R\&D subsidy and the composition of private R\&D," Research Policy, vol. 46, no. 8, pp. 1465-1478, 2017.

[12] M.-C. M. Chen and S. Gupta, "The incentive effects of R\&D tax credits: an empirical examination in an emerging economy," Journal of Contemporary Accounting \& Economics, vol. 13, no. 1, pp. 52-68, 2017.

[13] M. G. M. G. Colombo, A. Croce, and M. Guerini, "The effect of public subsidies on firms' investment-cash flow sensitivity: transient or persistent?" Research Policy, vol. 42, no. 9, pp. 1605-1623, 2013.

[14] D. Czarnitzki and A. A. A. A. Toole, "Business R\&D and the interplay of R\&D subsidies and product market uncertainty," Review of Industrial Organization, vol. 31, no. 3, pp. 169-181, 2007.

[15] D. Czarnitzki, B. Ebersberger, and A. Fier, "The relationship between R\&D collaboration, subsidies and R\&D performance: empirical evidence from Finland and Germany," Journal of Applied Econometrics, vol. 22, no. 7, pp. 1347-1366, 2007.

[16] F. Szücs, "Research subsidies, industry-university cooperation and innovation," Research Policy, vol. 47, no. 7, pp. 12561266, 2018.

[17] K.-N. K. Kang and H. Park, "Influence of government R\&D support and inter-firm collaborations on innovation in Korean biotechnology SMEs," Technovation, vol. 32, no. 1, pp. 68-78, 2012.

[18] M. Marino, S. Lhuillery, P. Parrotta, and D. . fnm Salaau, "Additionality or crowding-out? An overall evaluation of public R\&D subsidy on private R\&D expenditure," Research Policy, vol. 45, no. 9, pp. 1715-1730, 2016.

[19] H. Görg, M. Henry, and E. Strobl, "Grant support and exporting activity," Review of Economics and Statistics, vol. 90, no. 1, pp. 168-174, 2008.

[20] S. J. S. J. Wallsten, "The effects of government-industry R\&D programs on private $\mathrm{R} \& \mathrm{D}$ : the case of the small business innovation research program," The RAND Journal of Economics, vol. 31, no. 1, pp. 82-100, 2000.

[21] F. R. Lichtenberg, "The relationship between federal contract R\&D and company R\&D," The American Economic Review, vol. 74, no. 2, pp. 73-78, 1984.

[22] F. Yu, Y. Guo, K. Le-Nguyen, S. J. Barnesau, and W. Zhangau, "The impact of government subsidies and enterprises' R\&D investment: a panel data study from renewable energy in China," Energy Policy, vol. 89, pp. 106-113, 2016.

[23] P. Boeing, "The allocation and effectiveness of China's R\&D subsidies - evidence from listed firms," Research Policy, vol. 45, no. 9, pp. 1774-1789, 2016.

[24] T. Takalo, T. Tanayama, and O. Toivanen, "Market failures and the additionality effects of public support to private R\&D: theory and empirical implications," International Journal of Industrial Organization, vol. 31, no. 5, pp. 634-642, 2013.

[25] C. Schneeweiss, "Distributed decision making-a unified approach," European Journal of Operational Research, vol. 150, no. 2, pp. 237-252, 2003.

[26] W. Xiao and Y. Xu, "The impact of royalty contract revision in a multistage strategic R\&D alliance," Management Science, vol. 58, no. 12, pp. 2251-2271, 2012.

[27] M. Breton, A. Turki, and G. Zaccour, "Dynamic model of R\&D, spillovers, and efficiency of Bertrand and Cournot 
equilibria," Journal of Optimization Theory and Applications, vol. 123, no. 1, pp. 1-25, 2004.

[28] T. Takalo and T. Tanayama, "Adverse selection and financing of innovation: is there a need for R\&D subsidies?" The Journal of Technology Transfer, vol. 35, no. 1, pp. 16-41, 2010.

[29] X. Chen, K. Li, F. Wang et al., "Optimal production, pricing and government subsidy policies for a closed loop supply chain with uncertain returns," Journal of Industrial \& Management Optimization, vol. 13, no. 5, pp. 1-26, 2017.

[30] J.-Y. J. Chen, S. Dimitrov, and H. Pun, "The impact of government subsidy on supply chains' sustainability innovation," Omega, vol. 86, pp. 42-58, 2019.

[31] S. R. S. R. Bhaskaran and V. Krishnan, "Effort, revenue, and cost sharing mechanisms for collaborative new product development," Management Science, vol. 55, no. 7, pp. 1152$1169,2009$.

[32] Y. Wang, B. Niu, and P. Guo, "On the advantage of quantity leadership when outsourcing production to a competitive contract manufacturer," Production and Operations Management, vol. 22, no. 1, pp. 104-119, 2013.

[33] B. Niu, Y. Wang, and P. Guo, "Equilibrium pricing sequence in a co-opetitive supply chain with the ODM as a downstream rival of its OEM," Omega, vol. 57, pp. 249-270, 2015.

[34] V. Krishnan and S. Bhattacharya, "Technology selection and commitment in new product development: the role of uncertainty and design flexibility," Management Science, vol. 48, no. 3, pp. 313-327, 2002.

[35] D. Olausson, C. Berggren, L. P. Universitet et al., "Managing uncertain, complex product development in high-tech firms: in search of controlled flexibility," Re D Management, vol. 40, no. 4, pp. 383-399, 2010.

[36] Ö.Ö. ÖzdemirÖzdemir, M. Denizel, and V. D. R. V. D. R. Guide, "Recovery decisions of a producer in a legislative disposal fee environment," European Journal of Operational Research, vol. 216, no. 2, pp. 293-300, 2012.

[37] G. Iyer and D. A. D. A. Soberman, "Social responsibility and product innovation," Marketing Science, vol. 35, no. 5, pp. 727-742, 2016.

[38] S. H. S. H. Yoo and T. Cheong, "Quality improvement incentive strategies in a supply chain," Transportation Research Part E: Logistics and Transportation Review, vol. 114, pp. 331-342, 2018.

[39] B. C. B. C. Giri, A. Chakraborty, and T. Maiti, "Quality and pricing decisions in a two-echelon supply chain under multimanufacturer competition," The International Journal of Advanced Manufacturing Technology, vol. 78, no. 9-12, pp. 1927-1941, 2015.

[40] A. Dechezleprêtre, E. Einiö, R. Martin et al., "Do tax incentives for research increase firm innovation? An RD design for R\&D," National Bureau of Economic Research, Cambridge, MA, USA, 22405, 2016.

[41] R. Bronzini and P. Piselli, "The impact of R\&D subsidies on firm innovation," Research Policy, vol. 45, no. 2, pp. 442-457, 2016.

[42] K. Aerts and T. Schmidt, “Two for the price of one?" Research Policy, vol. 37, no. 5, pp. 806-822, 2008.

[43] X. Dai and L. Cheng, "The effect of public subsidies on corporate R\&D investment: an application of the generalized propensity score," Technological Forecasting and Social Change, vol. 90, pp. 410-419, 2015.

[44] A. Dixit, "A model of duopoly suggesting a theory of entry barriers," The Bell Journal of Economics, vol. 10, no. 1, pp. 22-32, 1979.
[45] N. Singh and X. Vives, "Price and quantity competition in a differentiated duopoly," The RAND Journal of Economics, vol. 15, no. 4, pp. 546-554, 1984.

[46] J. Haraguchi and T. Matsumura, "Cournot-Bertrand comparison in a mixed oligopoly," Journal of Economics, vol. 117, no. 2, pp. 117-136, 2015.

[47] P. Lin and K. Saggi, "Product differentiation, process R\&D, and the nature of market competition," European Economic Review, vol. 46, no. 1, pp. 201-211, 2002.

[48] G. Symeonidis, "Comparing Cournot and Bertrand equilibria in a differentiated duopoly with product R\&D," International Journal of Industrial Organization, vol. 21, no. 1, pp. 39-55, 2003.

[49] A. A. A. A. Tsay and N. Agrawal, "Channel dynamics under price and service competition," Manufacturing \& Service Operations Management, vol. 2, no. 4, pp. 372-391, 2000.

[50] X. Shang, "The price war in the color TV industry does not attract consumers," 2019, http://www.ccn.com.cn/m/view. php?aid $=468100$.

[51] A. B. Jaffe and T. Le, "The impact of R\&D subsidy on innovation: evidence from New Zealand firms," Economics of Innovation and New Technology, vol. 26, no. 5, pp. 429-452, 2016. 